\title{
REPERTORIO BIBLIOGRÁFICO
}





\title{
NUEVOS Y VIEJOS PROBLEMAS EN LA REGULACIÓN JURÍDICO-CONSTITUCIONAL DE PARTIDOS POLÍTICOS EN ESPAÑA. REPERTORIO BIBLIOGRÁFICO (2001-2014)
}

\author{
MERCEDES IGLESIAS BÁREZ \\ Profesora Contratada Doctorada de Derecho Constitucional \\ Universidad de Salamanca
}

SuMARIO

Nota preliminar.

I. Partidos políticos, Democracia, Representación política y Elecciones.

II. Prohibición y disolución de partidos políticos.

III. Financiación de partidos políticos.

IV. Democracia paritaria y cuotas electorales.

V. Democracia interna y partidos políticos.

VI. Corrupción y partidos políticos.

VII. Partidos políticos y Territorio.

\section{NOTA PRELIMINAR}

Basta una simple mirada al funcionamiento actual de los Estados de democracia pluralista para que advirtamos que los partidos políticos son, como acertadamente apuntó la doctrina italiana, los «príncipes modernos» de nuestra Democracia. Se ha señalado que en pocas ramas del derecho constitucional como en ésta, la relación entre política y derecho alcanza tal trascendencia. Por otra parte, como señalara Grimm, el Derecho de Partidos es una variable dependiente del principio democrático, de tal modo que la concreta configuración de una democracia tiene no poco que ver con la posición jurídica y la condición fáctica de sus partidos. Ha sido, sin embargo, la propia evolución de esta «forma contemporánea de gobierno» la que indirectamente ha revalorizado la trascendencia del Derecho de Partidos. Las distorsiones que en la actualidad experimenta la democra- 
cia del Estado de partidos muestran que la relación entre democracia, pluralismo y partidos políticos es menos pacífica de lo que a primera vista pudiera parecer. El constitucionalista del presente no puede permanecer indiferente ante el evidente déficit de legitimación democrática del Estado y tampoco puede realizar reflexión alguna sobre los partidos sin poner de manifiesto la devaluación de los mismos como lugar de identificación colectiva. Una crisis de valoración social a la que se añaden sus insuficiencias funcionales y representativas. Da la impresión de que la representación política hubiera cambiado en las formas a través de los partidos, pero que acentuara los rasgos de pérdida del sentido relacional y de elitismo que ya tuviera su construcción tradicional. Con esto no se quiere obviamente restar legitimidad al principal instrumento de participación popular que posee la democracia contemporánea, ni apuntarse sin más a soluciones que en la actualidad se plantean en meros términos de sustitución de la democracia representativa. Pero es cierto que la situación está lejos de ser satisfactoria y que en ese contexto, y con una visión realista, el Derecho de Partidos puede adquirir una nueva significación. Si el constitucionalismo es limitación del Poder en favor de la libertad, no cabe duda de que el actual Derecho de partidos se convierte en una exigencia más del Estado de Derecho. Nuestra doctrina más solvente se replantea, pues, los problemas que en el Derecho de Partidos se derivan de la situación de los partidos en el Estado y no sólo de su estatuto frente al Estado. Las conexiones con el derecho electoral o el parlamentario, junto con los temas de financiación política o el efectivo principio de igualdad de partidos, convierten a esta materia en un elemento central del debate en torno a la calidad de nuestra democracia pluralista.

Este número monográfico dedicado a los partidos políticos se acompaña, como es costumbre, de un Repertorio bibliográfico sobre la regulación jurídico-constitucional de los partidos políticos en España en el período 2001-2014. La idea-fuerza con el que ha sido articulado este elenco bibliográfico ha sido fundamentalmente la de realizar un diagnóstico de nuestro Derecho de partidos, la de presentar el escenario que revele las preocupaciones y los problemas jurídico-políticos de nuestra democracia en los últimos años. Es un lugar común la advertencia sobre la complejidad que entraña este tipo de repertorios y sobre los retos que plantea en cuanto a su alcance o su metodología; una dificultad que se acentúa especialmente en un territorio como éste en el que convergen diversas miradas (jurídicas, sociológicas y politológicas), todas ellas igualmente necesarias y complementarias. No obstante, para que el repertorio fuera una imagen maestra de la regulación jurídico-constitucional de los partidos políticos en España, un balance que mostrara las tendencias de nuestro Derecho de partidos y desvelara hacia dónde transita nuestro Estado de partidos, he limitado el alcance a los estudios fundamentalmente jurídicos y publicados en España. En relación a los temas tratados, no se ha partido, como pudiera parecer, de los «topois» propios del Derecho de partidos (derecho electoral, financiación de partidos...) y «buscado» a continuación la literatura correspondiente, sino que más bien la metodología ha 
sido la inversa. En realidad, los problemas de los últimos años de nuestro Derecho de partidos «me han buscado a mí», por lo que en el sumario aparecen las cuestiones a las que más se ha dedicado la doctrina española en este período.

Algunas de ellas pueden ser consideradas «problemas clásicos» que arrastra la democracia española desde la transición política, una democracia que sin tránsito ni evolución nace como partitocracia. Así, podemos hablar de «continuismo» cuando se tratan cuestiones como la democracia y el papel de los partidos políticos, la representación política o el sistema electoral español y sus posibles reformas. No obstante, y a pesar de ser «viejos problemas», ya abundantemente tratados, es necesario subrayar que desde el año 2011 existe una tendencia más acusada a tratar la crisis de la representación política, la propuesta de mecanismos de democracia directa en términos más desnudos de contraposición o sustitución de la democracia representativa, o la llegada de la «democracia indignada» y la creación de nuevos partidos políticos que pretenden conjurar la cada vez más creciente desafección política. En esta misma línea continuista podemos incluir también la financiación de los partidos, la democracia interna partidaria o la corrupción política, cuestiones todas ellas, por otra parte, relacionadas entre sí. Siguen siendo abundantes los estudios sobre la financiación de los partidos políticos, especialmente tras la aprobación de LO 8/2007, de Financiación de partidos políticos y su posterior reforma mediante la LO 5/2012. Un análisis histórico de nuestro Derecho en materia de financiación de partidos muestra en términos generales que estamos ante una legislación «reactiva», que responde a la «occasio» del momento, ya sea para embridar los escándalos de financiación ilegal de los partidos, o bien para «ajustar» la financiación pública de los partidos a la crisis económica. La última reforma de 2012 ha puesto de manifiesto una realidad ante la cual el Derecho de Partidos ha mostrado siempre sus innatas limitaciones reguladoras. Así, algunos de sus buenos propósitos quedan frustrados por la «gateras» legales que permiten la huida de los partidos. El enfoque diacrónico de la legislación de financiación de partidos nos ayuda a la compresión del actual sistema financiación de los partidos. No cabe duda de que las especiales necesidades del Decreto de 1977, de una regulación consciente y dirigida durante la transición política a establecer un régimen estable de pluralismo político han determinado los «rasgos genéticos» de nuestro modelo de financiación, no sólo en cuestiones como el desbordamiento de la financiación pública, que sigue siendo desmesurada, sino también de su dependencia y relación con el sistema electoral, cuestiones todas ellas a las que no da respuesta la Ley Orgánica 5/2012. Por otra parte, la doctrina se muestra también atenta a la problemática cuestión de la exigencia de democracia interna en los partidos analizando principalmente la selección de candidatos, o de la corrupción política. No podemos olvidar que en nuestros actuales Estados democráticos se forma un triángulo mágico: corrupción política-desafección política-discursos políticos antidemocráticos, de los que los resultados de las últimas elecciones europeas o el Índice de Transparencia In- 
ternacional de Percepción de la Corrupción de 2013, que considera a España como el segundo país del mundo donde más ha aumentado la percepción de la corrupción, no son más que una muestra. La mayor parte de la doctrina pone de manifiesto que en nuestro país ha existido un excesivo protagonismo del derecho penal en la lucha contra la corrupción política, y cómo sólo la «ilusión de los juristas» puede hacer pensar que la corrupción se ataja a golpe de Código penal. La lucha contra la corrupción no es sólo un problema jurídico, sino como acertadamente ha mostrado la doctrina más atenta, un estadio sociológico-moral de degradación.

Nuestro Derecho de Partidos ha mostrado, por otra parte, en los últimos años su atención por otras cuestiones, que se han convertido en las nuevas tendencias de la normativa partidaria: la prohibición e ilegalización de partidos políticos, la democracia paritaria y, en menor medida, la aparición de una dimensión territorial en el estudio de los partidos, fundamentalmente enfocada al análisis de los partidos políticos europeos y su papel en el proceso de integración europea, así como de los partidos políticos a nivel autonómico. No cabe duda de que el aspecto más decisivo y la clave que permite entender la génesis y la propia estructura de la Ley 6/2002 de Partidos políticos viene determinado por la apuesta del legislador por introducir en el Derecho español un mecanismo eficaz de prohibición de partidos políticos que apoyaban y sustentaban políticamente el terrorismo de ETA. El ámbito material, pues, de la Ley es la lucha contra el terrorismo y este aspecto ha determinado sus rasgos genéticos y, en concreto, las dos paradojas principales en las que incurre esta normativa. La primera de ellas consistiría en presentarse como una regulación general del estatuto jurídico de los partidos, cuando en realidad está directamente orientada a posibilitar la ilegalización de unas concretas formaciones políticas que apoyan la violencia terrorista. Esta finalidad, por otra parte, ha marcado la trayectoria de la Ley, desde su creación por los dos partidos políticos mayoritarios, extramuros del Parlamento, hasta su propia arquitectura, donde resulta evidente la desproporción entre las previsiones normativas referidas a la libertad de creación de partidos políticos o la democracia interna, y las que tienen por objeto el control de la libertad de actuación partidaria y la posible disolución del partido. La Ley no pretende, pues, superar las carencias de la vieja normativa, sino posibilitar la ilegalización de partidos por la realización de actividades antidemocráticas, regular, pues, no el estatuto jurídico-constitucional de los partidos, sino unas concretas patologías. Razones de oportunidad política y la urgencia por tener «el problema resuelto» de cara a las elecciones locales de 2003, marcaron de nuevo el Derecho de partidos en España. Lo que pudo ser la regulación de una insuficiencia del de la Ley de 1978, se convirtió en la razón de ser de la Ley y lastró su valoración. Es evidente que de algún modo nos encontramos ante una ley general con una finalidad ad cassum. Y enlazamos así con la segunda paradoja. Como se subrayará pronto, si una primera lectura de la Ley parece llevar a la conclusión de que nos encontramos ante un conjunto 
normativo de cláusulas garantistas de la libertad de asociación de los partidos, lo cierto es que la Ley, sesgada por su propia finalidad, adquiere a la postre un claro matiz de limitación de derechos. Con estas consideraciones, obviamente, no se pretende cuestionar la trascendencia de la Ley como norma fundamental de nuestro Derecho de partidos. Tan sólo remarcar que, a mi juicio, esta regulación es, en buena medida, una ocasión perdida para profundizar en la regulación constitucional de un ámbito esencial del moderno Estado democrático. Por otra parte, garantizar el valor del pluralismo político y la apertura del proceso político es la verdadera ratio que puede justificar el establecimiento del principio de constitucionalidad de las actividades externas de los partidos. Se trataría en suma de proteger, en palabras de Meier, no ya al Estado, sino a la legalidad democrática, que entendida como libre autoorganización de la sociedad es, en el fondo, el «instrumento constitucional de la evolución política». No me es ajeno, por otra parte, que es aquí donde con más crudeza aparece la contradicción que conlleva una decisión de este carácter. La apertura del proceso político democrático se garantiza «cerrando» el paso a determinadas formaciones políticas, por lo que la medida disolutoria afecta, en último término, tanto a la legitimidad del sistema político, como al entendimiento incluyente de la propia Comunidad que se encuentra en su base. Y podría añadirse, que ésta no es inocua frente a los valores y derechos fundamentales que intentan salvaguardarse con tal medida. Éste fue, pues, el centro del problema político y constitucional que planteaba la Ley Orgánica 6/2002, de 27 de junio, de Partidos Políticos y al que la doctrina se ha dedicado principalmente en los últimos años. Entre las nuevas líneas de nuestro Derecho de partidos también se encuentran finalmente los abundantes estudios de la democracia paritaria y las cuotas electorales. La Disposición Adicional Segunda de la Ley de Igualdad entre mujeres y hombres de 2007 introdujo las cuotas electorales bajo la fórmula del principio de composición equilibrada de las listas electorales (40-60) y desde entonces la doctrina se ha enfrentado tanto a las dudas de validez de la normativa, que basculan en el delicado terreno de los derechos fundamentales y los principios constitucionales (la igualdad, el derecho de sufragio pasivo, la libertad de asociación de los partidos políticos, la libertad ideológica y el principio de unidad de representación), como a las dificultades de su articulación y efectividad. En el caso español se ha mostrado que ya se partía de una situación de equilibrio en la composición de las listas y de los parlamentos (en torno al $39 \%$ ), y que la ley ha mantenido en términos generales este porcentaje, cuando no lo ha reducido. A ello ha contribuido, sin duda, los rasgos del sistema electoral español (listas cerradas, circunscripciones electorales pequeñas) y la propia actitud de los partidos políticos, que relegan a las mujeres a los puestos inferiores de la listas. Por otra parte, la previsión del art. 44 bis LOREG ha evidenciado otras distorsiones jurídico-constitucionales como la dificultad de conciliar esta exigencia con la apertura de las listas, cuestiones todas ellas abiertas y que serán sin duda objeto de estudio en el futuro. 


\section{PARTIDOS POLÍTICOS, DEMOCRACIA, REPRESENTACIÓN POLÍTICA Y ELECCIONES}

\section{Libros y Capítulos de Libros}

AA.VV.: El Informe del Consejo de Estado sobre la Reforma Electoral. CEPC, Madrid, 2009, pp. $705-731$.

Alcántara, M.; Ramón Montero, J.: Curso de Partidos Políticos. Akal, Madrid, 2003.

Alguacil GonZÁleZ-Aurioles, J.: Estado de partidos: participación y representación, Marcial Pons, 2013.

Allue Buiza, A. y otros: Recursos documentales para las jornadas: el pluralismo político en el convenio europeo de derechos humanos y su aplicación en el régimen de los partidos políticos: jueves 8 y viernes 9 de marzo de 2007. Valladolid Centro de Documentación Europea. Universidad de Valladolid, 2007.

Álvarez Conde, Enrique (Catalá i Bas, Alexandre H. (colab.)): El Derecho de Partidos, Ed. Colex, Madrid, 2005.

Aragón, M.: Proclamación de candidaturas y garantías electorales: propuestas de reforma, CEPC, Madrid, 2008.

Arnaldo Alcubilla, Enrique: El carácter dinámico del régimen electoral español, Ed. Centro de Estudios Políticos y Constitucionales, Madrid, 2002.

Arnaldo, E.; Avila, R. y Oroz, J. J.: Elecciones y Justicia en España y México, Tribunal Electoral del Poder Judicial de la Federación de México, 2002.

Arruego RodríGuez, G.: Representación política, participación política representativa y mediación partidista del vínculo entre representantes y representados en la CE de 1978. En Transfuguismo político: escenarios y respuestas/coord. por Pablo Santolaya Machetti, Jesús María Corona Ferrero, María Díaz Crego, 2009.

Bastida Freijedo, F.J. y otros: Parlamento y partidos políticos: XV Jornadas de la Asociación Española de Letrados de Parlamentos. Madrid: AELPA, Tecnos, 2009.

Bautista PlazA, D.J.: La función constitucional de los partidos políticos de concurrir a la formación y manifestación de la voluntad popular, Universidad de Granada, 2003.

Biglino Campos, P.: «La Legislación Electoral Estatal y el Margen del Legislador Autonómico». GÁlvez MuÑoz, L. A. (dir.): El Derecho Electoral de las Comunidades Autónomas. Revisión y Mejora. Cuadernos y Debates, Centro de Estudios Constitucionales, Madrid, 2009.

Blanco Valdés, R. L.: Las Conexiones Políticas: Partidos, Estado, Sociedad. Alianza Editorial, Madrid, 2001.

CANo Bueso, J.: «En torno a las transformaciones de la representación política». En La democracia constitucional: estudios en homenaje al profesor Francisco Rubio Llorente, Vol. 1, 2002.

Carraco Duran, M.: Grupos parlamentarios y Ley de Partidos. La organización interna de la Cámara y el Poder Judicial, en Relaciones entre el Poder Legislativo y el Poder Judicial, Parlamento Vasco, Vitoria, 2007.

Chueca Rodríguez, R. L.: La representación política: una conjetura colectiva. En Constitución y democracia: ayer y hoy: libro homenaje a Antonio Torres del Moral, Vol. 1, 2012. 
Cohn-Bendit, D.: ¿'Contra los partidos políticos!?: reflexiones de un apátrida sin partido. Madrid: Los Libros de la Catarata, 2013.

Costafreda i Quesada, A.: Partidos políticos y democracia. En A los príncipes republicanos: gobernanza y desarrollo desde el republicanismo cívico/coord. por Joan Prats i Catalá, 2006.

Criado Olmos, H.: Los partidos políticos como instrumentos de democracia. Madrid, Fundación Alternativas, 2005.

Díaz Revorio, F.J.: Breves reflexiones sobre Democracia y Representación Política: Desde la Edad Antigua al Estado Social y Democrático del Derecho. En Democracia en el mundo antiguo y en la actualidad/coord. por Alicia Valmaña Ochaíta, 2013.

Duque Villanueva, J.C. y Requejo Pagés, J.L.: «Artículo 6», en M. Emilia Casas BaAmonde y Miguel Rodriguez Piñero y Bravo Ferrer: Comentarios a la Constitución Española, Fundación Wolters Kluwer, Madrid, 2009.

- Elecciones Políticas y Tribunal Constitucional. Jurisprudencia constitucional en materia electoral 1980-2005, Cuadernos Aranzadi del Tribunal Constitucional. Ed. Aranzadi, Navarra, 2006.

Duverger, M.: Los partidos políticos, Madrid F.C.E. de España 2002.

Fernández Alles, J.J.; Eliche Moral, D.: Crisis de la representación política en España e Italia (2007-2013): reformas, influencias y perspectivas. En Democracia, gobernanza y participación/coord. por María Isabel Garrido Gómez, Ramón Ruiz Ruiz, 2014.

Fernández Sarasola, I.: Los partidos políticos en el pensamiento español: de la ilustración a nuestros días, Madrid, Marcial Pons, 2009.

Fernández Vivas, Y.: Igualdad de oportunidades de los partidos políticos y sistema electoral (a propósito de la reforma del Senado). En El Estado autonómico: integración, solidaridad, diversidad/coord. por Miguel Angel García Herrera, José María Vidal Beltrán; Jorge Sevilla Segura (pr.). Vol. 2, 2005.

FernándeZ-Miranda CAmpoAmor, A.: «Sobre la Reforma Electoral». AA.VV.: El Informe del Consejo de Estado sobre la Reforma Electoral. CEPC, Madrid, 2009, pp. 673-704.

Fernández-Miranda Campoamor, Carmen y Fernández-Miranda Campoamor, Alfonso: Sistema electoral, Partidos Políticos y Parlamento, Ed. Colex. Madrid, 2003.

Flores Juberías, C.: Revolución francesa y representación política: el debate teórico. En Constitución y democracia: ayer y hoy: libro homenaje a Antonio Torres del Moral, Vol. 1, 2012.

Gálvez Muñoz, L. A. (dir.): El Procedimiento Electoral en Leyes Electorales Autonómicas». El Derecho Electoral de las Comunidades Autónomas. Revisión y Mejora. Cuadernos y Debates, Centro de Estudios Constitucionales, Madrid, 2009.

García GaITÁN, C.: Algunas reflexiones sobre la representación política. En Ciudadanía y política/coord. por Francesc Pau i Vall; Fernando Vallespín Oña (aut.), 2004.

Garcia Guerrero, J.L.: Escritos sobre partidos políticos. Como mejorar la democracia, Ed. Tirant lo Blanch, Valencia, 2008.

García Guitián, E.: Problemas de la representación política. En Teoría política: poder, moral, democracia/coord. por Aurelio Arteta Aisa, Elena García Guitián, Ramón Máiz Suárez, 2003. 
: Sobre la representación política: expectativas, transformaciones y adaptación a nuevos contexto. En Deliberación pública y democracias contemporáneas/coord. por María Elena Beltrán Pedreira, Fernando Vallespín Oña, 2012.

GARCía RocA, J.: «Representación política y transfuguismo: la libertad de mandato», en P. Santolaya y J.M Ma Corona (dir.) y M. Díaz Crego (coord.): Transfuguismo político: escenarios y respuestas. Cizur Menor, Civitas/Thomson Reuters, 2009.

GreppI, A.: Representación política y deliberación democrática. Cuaderno gris, ISSN 0213-6872, no 9, 2007 (Ejemplar dedicado a: Democracia, deliberación y diferencia/coord. por Mariano C. Melero de la Torre).

Grimm, Dieter: «Los partidos políticos», en Benda, Maihofer, Vogel, Hesse y Heyde: Manual de Derecho Constitucional. Ed. Marcial Pons, Madrid, 2001.

GutiérRez GutiérRez, I. (coord.): La democracia indignada: tensiones entre voluntad popular y representación política, Comares, 2014.

Herbert Aldrich, J.: ¿Por qué los partidos políticos?: una segunda mirada. Madrid. Centro de Investigaciones Sociológicas, 2012.

Herrero De Miñon, M.: «Los Partidos como Estamentos Privilegiados: Ideas para su Reforma». La Democracia Constitucional. Estudios en Homenaje al Prof. Francisco Rubio Llorente. CEPC, Madrid, 2003.

Holgado GonzÁlez, M. Partidos y representación política. En Derecho constitucional para el siglo XXI: actas del VIII Congreso Iberoamericano de Derecho Constitucional/coord. por Manuel Carrasco Durán, Francisco Javier Pérez Royo, Joaquín Urías Martínez, Manuel José Terol Becerra, Vol. 2, 2006.

Jimenez Campo, J.: «Partidos Políticos». Aragón Reyes, M. (coord.): Temas Básicos de Derecho Constitucional - Tomo I. Derecho Constitucional y Fuentes de Derecho. Civitas, Madrid, 2001.

- :Pluralismo Político». Aragón Reyes, M. (coord.): Temas Básicos de Derecho Constitucional — Tomo I. Derecho Constitucional y Fuentes de Derecho. Civitas, Madrid, 2001.

Jiménez Campo, Javier voz: 'Registro de partidos políticos', en Temas básicos de Derecho Constitucional, Aragón Reyes, Manuel (coord.) Ed. Civitas, Madrid 2001.

López Nieto, L.; Delgado Sotillos, I.: Comportamiento político y sociología electoral. Madrid, Universidad Nacional de Educación a Distancia, 2008.

Maravall, J.M.: Las promesas políticas. Barcelona, Galaxia Gutenberg/Círculo de Lectores, 2013.

Martínez Cuadrado, M.A.; Mella Márquez, M. (coords.): Partidos políticos y sistemas de partidos. Trotta, 2012.

Martínez Cuevas, M. D.: El Régimen Jurídico de los Partidos Políticos. Marcial Pons, Madrid, 2006.

Martínez Ruano, P.: El control electoral. Ed. Congreso de los Diputados, Madrid, 2003. Martinez, A. (coord.): Representación y calidad de la democracia en España. Tecnos, 2006.

Martínez-Pujalte, A. L.: El Sistema Electoral Español: Contribución a un Debate. Fundación Ciudadanía y Valores, Madrid, 2008.

Mella Márquez, M.; Abreu Fernández, V. et al: Curso de partidos políticos. Madrid, Akal, 2003.

MÉndeZ Lago, M.; Ramiro FernándeZ, L.; KATZ, R. et al: Las transformaciones contemporáneas de los partidos políticos, Madrid, Zona Abierta, 2004. 
Menéndez Alzamora, M. (coord.): Participación y representación política. Tirant lo Blanch, 2009.

Montero Gibert, J.R.: Los estudios sobre los partidos políticos: una revisión crítica. Conocimiento y realidad: estudios en homenaje a Jorge Riezu Martínez/coord. por José Antonio Portero Molina, 2004.

- (aut.); Ghünter, R. (aut); Linz, J.J. (aut.); Monterroso Casado (trad.): Partidos políticos: viejos conceptos y nuevos retos. Trotta: Fundación Alfonso Martín Escudero, 2007.

Moreno Juste, A.: Los partidos políticos minoritarios: ¿cómo ven la política exterior? En Política exterior española: un balance de futuro/coord. por José María Beneyto Pérez, Juan Carlos Pereira Castañares, Vol. 2, 2011.

Morodo, R. y Murillo De la Cueva, P.L.: El ordenamiento constitucional de los partidos políticos Ed. Universidad Autónoma de México, México 2001.

Nohlen, D.: Sistemas electorales y partidos políticos. México. Fondo de Cultura Económica, 2004

Oliver Araujo, J.; Calafell Ferrá, V.J.: Los estatutos de los partidos políticos españoles: (partidos con representación parlamentaria. Madrid, Boletín Oficial del Estado. Centro de Estudios Políticos y Constitucionales, 2007.

Orosa GonzÁlez, J.J.: El marketing de los partidos políticos: la lucha por el poder. Villafranca del Penedés, Barcelona, Erasmus, 2009.

Pau Vall, F.; Asociación Española de Letrados de Parlamentos: Parlamento y partidos políticos. Madrid. Tecnos, 2009.

Pedrosa, F.: Las redes transnacionales de partidos políticos ¿Tradicionalismo, política interna o diplomacia partidaria?. En Participación democracia y gestión de la escasez: experiencias de democracia y participación/coord. por Rafael Bañón i Martínez, Rubén Tamboleo García, Gema Sánchez Medero, 2013.

Porras Martínez, J.M.: Régimen jurídico de los partidos políticos en la historia constitucional de España. XXV Aniversario de la Constitución Española: propuestas de reforma/coord. por María Luisa Balaguer Callejón, 2004.

Porras Nadales, A.J.: Nuevos significados de la representación política. En Estudios de teoría del Estado y derecho constitucional en honor de Pablo Lucas Verdú/coord. por Raúl Morodo Leoncio, Pedro de Vega García, Vol. 1, 2001.

Porras Ramírez, J.M.: Los partidos políticos como instrumentos al servicio de la formación y expresión de la voluntad popular. En Constitución y democracia: 25 años de Constitución democrática en España:(Actas del Congreso celebrado en Bilbao los días 19 a 21 de noviembre de 2003)/coord. por Miguel Angel García Herrera, Vol. I, 2005.

Quirosa-Cheyrouze MuÑOz, R. (coord.): Los partidos en la Transición: las organizaciones políticas en la construcción de la democracia española. Biblioteca Nueva, 2013.

RAmirez, M.: Consenso, Constitución y partidos políticos, una reflexión crítica 26 años después. Barcelona, Institut de Ciéncies Politiques i Socials 2006.

Rebollo Delgado, L.: Representación política y Parlamento. En Treinta años de Constitución/coord. por Francisco Javier García Roca, Enoch Albertí Rovira, 2010, pp. 991-1022.

- Partidos Políticos y Democracia. Dykinson, Madrid, 2007.

Reniu i Vilamala, J.M.: Giovani Sartori y el estudio de los partidos políticos. En Para leer a Sartori/coord. Por José Ramón López Rubí Calderón, 2009. 
RIEzU, J.: Crisis y ocaso de los partidos políticos: causas, reflexión crítica y otros ensayos. Salamanca, Editorial San Esteban, 2013.

Rodríguez Blanco, V.: La fractura: ciudadanos partidos políticos. En Participacion, democracia y gestión de la escasez: experiencias de democracia y participación/ coord. Por Rafael Bañón i Martínez, Rubén Tamboleo García, Gema Sánchez Medero, 2013.

Rodriguez, X.R.: O Triunfo do galeguismo opnión pública, partidos polítcos e comporamento electoral na transición autonómica. Dykinson, 2009.

SÁNCHEZ, R.: El control audiovisual de las campañas electorales: influencia de las estrategias comunicativas de los partidos políticos en el discurso informativo de televisión: la campaña electoral de 2008 en España. Madrid, Fragua, 2014.

Santolaya Machetti, P.: Procedimiento y garantías electorales. Cizur Menor, Civitas/ Instituto de Derecho Parlamentario, 2013.

SAUQuillo GonZÁleZ, J.: Representación política y democracia. En Estado, justicia, derechos, 2002.

Serra Busquets, S.: Sistema de partidos políticos y resultados electorales en los Parlamentos de las Comunidades Autónomas (1980-2012). En El futuro territorial del estado español: ¿centralización, autonomía, federalismo o secesión?/coord. por Joan Oliver Araujo, María Ballester Cardell, Vicente Juan Calafell Ferrá, Alberto Oehling de los Reyes, 2014.

Soler, M.: Campañas Electorales y Democracia en España. Universitat Jaime, [s.1.], 2001.

SolozÁbal Echavarría, J.J.: Representación y partidos políticos. En Constitución y democracia: 25 años de Constitución democrática en España:(Actas del Congreso celebrado en Bilbao los días 19 a 21 de noviembre de 2003)/coord. por Miguel Angel García Herrera, Vol. I, 2005.

Tamboleo García, R.: La construcción del partido político PODEMOS. De Caracas a Somosaguas: la casta y los castatarios. En La modernización de la política y la innovación participativa/coord. Por Rafael Bañón i Martínez, Rubén Tamboleo García, 2014

Tomás Mallén, B.: Los partidos políticos y el fenómeno del préstamo de parlamentarios en España. En Derecho Constitucional para el siglo XXI: actas del VIII Congreso Iberoamericano de Derecho Constitucional, vol. 2, 2006.

Torres Del Moral, A.: «Sistemas Electorales y Sistemas de Partidos en las Comunidades Autónomas». GÁlvez MuÑoz, L. A. (dir.): El Derecho Electoral de las Comunidades Autónomas. Revisión y Mejora. Cuadernos y Debates, Centro de Estudios Constitucionales, Madrid.

Turco, G.: Bien común y representación política. En El bien común: cuestiones actuales e implicaciones político-jurídicas/coord. por Miguel Ayuso Torres, 2013.

VAllespín OÑA, F.: Ciudadanía y política coord. por Francesc Pau i Vall; Tecnos, 2004. VÁzQuez Yebra, J.; VÁzQuez Rolland, D.: La desafección social hacia los partidos políticos. Madrid, J. Vázquez, 2011.

Velasco Retamosa, J.M.: Democracia y partidos políticos. En Democracia en el mundo antiguo y en la actualidad/coord. por Alicia Valmaña Ochaíta, 2013, p. 223.

VelázQuez Álvarez, R.: El proceso constituyente europeo en sentido estricto, relanzar la integración desde la ciudadanía: el papel de los partido políticos como artífices de un tejido social democrático a escala europea. Madrid, Fundación Alternativa, 2006. 
Verge Mestre, T.: Partidos y representación política: las dimensiones del cambio en los partidos políticos españoles, 1977-2004. Madrid: Centro de Investigaciones Sociológicas, 2007.

Ware, A.: Partidos políticos y sistema de partidos. Tres Cantos, Madrid. Istmo 2004.

\section{Artículos de Revistas}

AA.VV.: «Encuesta: Régimen Electoral». Teoría y Realidad Constitucional. n 22, UNED, Madrid, 2008.

Abellán Artacho, P.: Representación política y democracia: aportaciones desde la Teoría de la Representación en los últimos diez años. Revista española de ciencia política, no 33, 2013.

Abellán Matesanz, I.: El proceso electoral desde la doctrina de la Junta Electoral Central. Revista Teoría y Realidad Constitucional, Año 2004, nº 14.

Albertí Rovira, E.: La representación territorial. En Fundamentos: Cuadernos monográficos de teoría del estado, derecho público e historia constitucional, no 3, 2004 (Ejemplar dedicado a: La Representación Política).

Alcántara SÁez, M.: Partidos políticos en América Latina: precisiones conceptuales, estado actual y retos futuros. Revista de Estudios Políticos, $\mathrm{n}^{\circ} 124$, Abril/Junio 2004.

Alguacil GonzÁlez-Aurioles, J.: De nuevo sobre el poder y los controles a los partidos políticos. A propósito de la reciente reforma de la LOREG sobre mociones de censura en el ámbito municipal. Revista General de Derecho Constitucional, $\mathrm{n}^{\mathrm{o}} 12,2011$.

Allúe Buiza, A.: Déficit parlamentario y representación política en la Unión Europea, Teoría y realidad constitucional, $\mathrm{n}^{\circ}$ 33, 2014 (Ejemplar dedicado a: La integración política de Europa (II)).

Álvarez Álvarez, L.: Modificar las normas de la Ley Orgánica 6/2002, de Partidos Políticos, que condicionan la construcción de la relación de representación a la identificación con fines democráticos. Debates constitucionales, nº 6, 2004.

Ariño Ortiz, G.: Partidos políticos y democracia en España. Así no podemos seguir. El Cronista del Estado Social y Democracia de Derecho, n 4, 2009.

Arruego Rodriguez, G.: «Representación política y régimen electoral», Cuadernos de Derecho Público, no 22-23 (mayo-diciembre, 2004).

Balaguer Callejón, M.L.: La relación entre los grupos parlamentarios y los partidos políticos en el ordenamiento jurídico-constitucional español. Corts: Anuario de Derecho Parlamentario, $\mathrm{n}^{\circ}$ 10, 2001.

Barbetta, P.; Bidaseca, K.: Reflexiones sobre el 19 y 20 de diciembre de 2001 «Piquete y cacerola, la lucha es una sola»: ¿emergencia discursiva o nueva subjetividad? Revista argentina de sociología, $\mathrm{n}^{\circ} 2,2004$.

Bravo De Laguna, J.H.: Partidos políticos, Estado y Derecho: de la hostilidad a la teoría. Anales de la Facultad de Derecho, no 19, 2002.

Brugué, Q.: Los partidos políticos en la democracia del siglo XXI. Gaceta Sindical: Reflexión y Debate, $\mathrm{n}^{\circ} 21,2013$.

BRunet, P.: Acerca del concepto de representación política. Revista internacional de pensamiento político, $\mathrm{n}^{\circ} 7,2012$. 
CaAmaño Domínguez, F. M.: Representación o participación de las minorías: sobre la determinación de algunos espacios constitucionales útiles a las políticas del reconocimiento. En Fundamentos: Cuadernos monográficos de teoría del estado, derecho público e historia constitucional, $n^{\circ}$ 3, 2004 (Ejemplar dedicado a: La Representación Política).

Candela Talavero, J. E.: La representación política y los derechos fundamentales: la participación y la información, CEFLegal: revista práctica de derecho. Comentarios y casos prácticos, $\mathrm{n}^{\circ} 166,2014$.

Carbonell Sánchez, M.: Representación política y espacio público. En Estudios de Política y Sociedad, $\mathrm{n}^{\circ}$ 1, 2006.

CArrasco Durán, M.: Sobre la reforma de la Ley Orgánica del Régimen Electoral General: un programa de mejoras técnicas. Revista Española de Derecho Constitucional, nº 79, Enero/Abril 2007.

Carreras Serra, F.: «Los partidos en nuestra democracia de partidos», Revista española de Derecho Constitucional, año 24, nº 70, enero-abril 2004.

- :Los Partidos en Nuestra Democracia de Partidos». Revista Española de Derecho Constitucional, año 24, $\mathrm{n}^{\circ}$ 70, 2004.

Cascajo Castro, J.L.: El Estado democrático: materiales para un léxico constitucional español. Revista Española de Derecho Constitucional, n 69 , Septiembre/Diciembre 2003

Catalá i BAs, A.H.: La inviolabilidad parlamentaria a la luz de la Ley de partidos políticas. Revista de Derecho Político, n 61, 2004.

- Transfuguismo y régimen jurídico de los concejales no adscritos. ¿Puede, y debe, el Derecho sancionar la deslealtad política?. Revista Española de Derecho Constitucional, n ${ }^{\circ}$ 101, Mayo/Agosto 2014.

CEBrián ZaZurCa, E.: La representación política como drama (A propósito de un ensayo de Francisco Ayala). Asamblea: revista parlamentaria de la Asamblea de Madrid, $\mathrm{n}^{\circ} 30,2014$

Chueca Rodríguez, R. L.: La quiebra de la representación política. En Fundamentos: Cuadernos monográficos de teoría del estado, derecho público e historia constitucional, $n^{\circ}$ 3, 2004 (Ejemplar dedicado a: La Representación Política).

- Representación política y representación de la política. En Asamblea: revista parlamentaria de la Asamblea de Madrid, ISSN 1575-5312, nº 13, 2005.

- Veinticinco años de representación política. Revista de derecho político, $\mathrm{n}^{\circ} 58$ 59, 2003-2004 (Ejemplar dedicado a: Balance de la Constitución en su XXV aniversario).

Colomer Viadel, A.: La independencia del Defensor del Pueblo frente a los partidos políticos. Teoría y Realidad Constitucional, n 26, 2010.

Colomer, J.M.: Son los partidos los que eligen los sistemas electorales (o las leyes de Duverger cabeza abajo). Revista Española de Ciencia Política, nº 9, 2003.

Concha Sequeiros, L.: Los partidos políticos: la democracia y la crisis de representatividad. Revista de la Asamblea Nacional de Rectores, nº 9, 2006.

Conde Calderón, J.: Representación política y prácticas electorales en et Caribe colombiano, 1820-1836. Anuario de Estudios Bolivarianos, $\mathrm{n}^{\circ}$ 11, 2004. 
Contreras Casado, M.: Democracia, partidos políticos y poder judicial: algunos problemas y tensiones en la limitación de los derechos. Estudios de Derecho Judicial, $\mathrm{n}^{\mathrm{o}} 106,2006$.

Cortés Rodas, F.: Los fundamentos normativos de la democracia y el problema de la representación política. En Res publica: revista de filosofía política, no 25, 2011 (Ejemplar dedicado a: De Spinoza a Blumenberg).

Costa, P.: El problema de la representación política: una perspectiva histórica. Anuario de la Facultad de Derecho de la Universidad Autónoma de Madrid, no 8, 2004 (Ejemplar dedicado a: La representación en el derecho).

Criado De Diego, M.: Sobre el concepto de representación política: lineamiento para un estudio de las transformaciones de la democracia representativa. Revista Derecho del Estado, no 28, 2012.

Criado, J.I. y García Alonso, R.: ¿Democracia 2.0? Un análisis del potencial deliberativo de la blogosfera política. Revista de Estudios Políticos, nº 155, Enero/Marzo 2012 .

Crouch, C.: Los partidos políticos de la postdemocracia, Claves de Razón Práctica, Madrid, $\mathrm{n}^{\circ}$ 141, Abr. 2004.

Cuenca Toribio, M.: En los orígenes de la España contemporánea: 1836-1839. El nacimiento de los partidos políticos y de la idea de progreso. Revista de Estudios Políticos, no 122, Oct-Dic 2003.

DAder, J.L.: Ciberpolítica En los websites de los partidos políticos la experiencia de las elecciones de 2008 en España ante las tendencias transnacionales. Revista de Sociología e Política, v17 n34, 2009.

Dalla Via, A.R.: El régimen electoral y los partidos políticos. Anuario Iberoamericano de justicia constitucional, $\mathrm{n}^{\circ} 8,2004$.

De Vega, P.: La democracia como proceso (Consideraciones en tomo al republicanismo de Maquiavelo). Revista de Estudios Políticos, nº 120, Abril/Junio 2003.

Decker, F.: Democracia directa en el partidista Estado Federal Alemán. Revista Teoría y Realidad Constitucional, Año 2007, n 19.

Delgado Fernández, S.: El complejo mapa de los particos «social-demócratas» en la España de la transición (1975-1979). Revista de Estudios Políticos no 135, Enero/ Marzo 2007.

DEMOCRACIA Y REPRESENTACIÓN HOY: dos palabras sobre la representación política en el Estado democrático-representativo.

Duso, G.: Génesis y lógica de la representación política moderna. En Fundamentos: Cuadernos monográficos de teoría del estado, derecho público e historia constitucional, n 3, 2004 (Ejemplar dedicado a: La Representación Política).

ENCUESTA SOBRE EL CONTROL DEL PODER Y QUIENES LO EJERCEN. Encuestados. Revista Teoría y Realidad Constitucional, Año 2013, n 31.

EnCUesta sobre el referéndum. Encuestados. Revista Teoría y Realidad Constitucional, Año 2012, n 30.

EnCUeSta sobre la RePresentación política. Revista Teoría y Realidad Constitucional, Año 2014, n 34.

Encuesta: Régimen electoral. Encuestados. Revista Teoría y Realidad Constitucional, Año 2008, n 22. 
Fernández Sarasola, I.: Idea de partido y sistema de partidos en el constitucionalismo histórico español. Revista Teoría y Realidad Constitucional, Año 2001, n 7.

— : La idea de partido político en la España del siglo XX. Revista Española de Derecho Constitucional, $\mathrm{n}^{\circ}$ 77, Mayo/Agosto 2006.

- ; GONZÁlEZ HernÁNDEZ, E.: Los partidos políticos en el pensamiento español: de la ilustración a nuestros días. Teoría y Realidad Constitucional, ISSN 1139$5583, \mathrm{n}^{\circ} 25,2010$.

FERnÁndeZ Vivas, Y.: El régimen de los partidos políticos en Alemania. Teoría y Realidad Constitucional, $\mathrm{n}^{\circ}$ 31, 2013.

GAmbino, S.: Relaciones entre sistema electoral, formato de partidos y forma de Gobierno en la experiencia parlamentaria española. Revista de Estudios Políticos, n ${ }^{\circ} 146$, Octubre/Diciembre 2009.

García Guerrero, J.L.: La ley orgánica 6/2002 de partidos políticos contiene algunos desarrollos constitucionales muy coherentes. En estudios sobre la Constitución Española: homenaje al profesor Jordi Solé Tura, Vol. 22008.

GARCía Guitián, E.: Crisis de la representación política: las exigencias de la política de la presencia. Revista de estudios políticos, $\mathrm{n}^{\circ} 111,2001$.

— : El significado de la representación política. Anuario de la Facultad de Derecho de la Universidad Autónoma de Madrid, nº 8, 2004 (Ejemplar dedicado a: La representación en el derecho).

- ; Cavero Cano, G.: La (siempre controvertida) representación política. Asamblea: Revista Parlamentaria de la Asamblea de Madrid, n 27, 2012.

García RocA, F.J.: Representación política y transfuguismo: la libertad. En Cuadernos de derecho público, $\mathrm{n}^{\circ}$ 32, 2007.

Garrorena Morales, A.: Tribunal Constitucional y sistema electoral de las Comunidades Autónomas. Una desafortunada jurisprudencia. Revista Española de Derecho Constitucional, $\mathrm{n}^{\circ}$ 83, Mayo/Agosto 2008.

Garrote De Marcos, M.: «El Informe del Consejo de Estado sobre Reforma del Sistema Electoral: Algunas Observaciones Acerca de las Posibilidades de Reforma del Sistema Electoral del Congreso de los Diputados». Cuadernos de Derecho Público. $n^{\circ}$ 36. Madrid, 2009.

Gómez Albarello, J.G.: El malestar de la democracia: acerca de la desconexión de la deliberación y la representación políticas. Reflexión política, Año 14, nº 28, 2012.

GonzÁlez Botija, F.: La regulación legal de los partidos políticos en España a la luz de su interpretación jurisprudencial. Revista General de Derecho Administrativo, $\mathrm{n}^{\circ}$ 7, 2004.

GonZalez V.H.M.: Partidos políticos y sociedad civil. Paradojas y reveses democráticos. Andamios v9 n18, 2012.

GonZÁlEZ-Ares FernándeZ, J.A.: El derecho de asociación y los partidos políticos en el constitucionalismo español. Anuario de la Facultad de Derecho de Ourense, $n^{\circ} 1$, 2012.

Guerrero Salom, E.: Comunicación política y campañas electorales en España: 2000 y 2008. Revista General de derecho Político Comparado, nº 108, 2011.

Guillén López, E.: El sistema electoral del Congreso de los Diputados. Principios constitucionales y recientes propuestas de reforma. Revista Española de Derecho Constitucional, no 92, Mayo/Agosto 2011. 
GuILLÉn, G.: La representación política y el principio de separación de poderes. Anuario filosófico, Vol. 36, n 75-76, 2003 (Ejemplar dedicado a: Participación: entre Filosofía y Política).

Holgado GonZÁlez, M.: Qué y a quienes representan hoy los partidos políticos. Sistema $\mathrm{n}^{\circ} 188,2005$.

Iglesias, E.: Partidos políticos y movimientos sociales. Modalidades y transformación de la acción política durante el siglo XX. Elecciones, Vol. 11, n 12, 2012.

Jiménez De Parga y Cabrera, M.: Los partidos políticos en las democracias del siglo XXI. Anales de la Real Academia de Ciencias Morales y Políticas, nº 85, 2008.

JimÉnez RodrígueZ, G.A.: El sistema electoral español y la reforma política improbable, Letras jurídicas: revista de los investigadores del Instituto de Investigaciones Jurídicas U. V., n 28, 2013.

Lasagabaster Herrarte, I.: Partidos políticos y grupos municipales: un debate no cerrado sobre sus relaciones jurídicas. Revista vasca de Administración Pública., $\mathrm{n}^{\circ} 98,2014$.

Lavilla Alsina, L: Condicionamiento del régimen parlamentario español consecuentes al sistema electoral. Revista Teoría y Realidad Constitucional, Año 2009, n 23.

López, V.H.M.: Partidos políticos: Un ejercicio de clasificación teórica. Perfiles Latinoamericanos, $\mathrm{n}^{\circ} 33,2009$.

Magdaleno Alegría, A.: Libertad de expresión y partidos políticos en la jurisprudencia del Tribunal Europeo de los Derechos Humanos. Anuario da Facultade de Dereito da Universidade da Coruña, n ${ }^{\circ}$ 11, 2007.

Martín De La Vega, A.: «Los Partidos Políticos y la Constitución de 1978. Libertad de Creación y Organización de los Partidos en la Ley Orgánica 6/2002». Revista Jurídica de Castilla y León, no extraordinario, 2004.

MARTínez, A.: La representación política y la calidad de la democracia. Revista mexicana de sociología, Año 66, nº 4 (oct.-dic.), 2004.

Monroy Antón, A.; Rodríguez López, A.: Reflexiones acerca de la naturaleza jurídica de los partidos políticos. Actualidad Administrativa, n 4, 2009.

Montero Gibert, J.R. y Gunther, R.: Los estudios sobre los partidos políticos: una revisión crítica. Revista de Estudios Políticos, n 118, Octubre/Diciembre 2002.

MOREno RodríGuEz-Alcalá, D.: Una aproximación a la concepción deliberativa de la democracia. Revista Teoría y Realidad Constitucional, Año 2005, nº 16.

Nogueira Martínez, D.: El ámbito de aplicación del estatuto legal de los respresentantes locales no adscritos. Anuario de Derecho Municipal, n ${ }^{\circ}$, 2011.

Oliver Araujo, J.; Calafell Ferra, J.C.: Los estatutos de los partidos políticos: notas sobre su singularidad jurídico-constitucional. Revista de Estudios Políticos, $\mathrm{n}^{\circ} 137$, 2007.

OÑate Rubalcaba, P.: Participación política ciudadana y actores para la intermediación y representación políticas en los albores del siglo XXI. En Arxius de sociologia, $n^{\circ}$ 11, 2004 (Ejemplar dedicado a: Participació i ciutadania).

Padró-Solanet, A.; Cardenal, A.S.: Partidos y política en Internet: Un análisis de los websites de los partidos políticos catalanes. IDP: Revista de Internet, derecho y política, $n^{\circ} 6,2008$.

Paramio Rodrigo, L.: Partidos y ciudadanía en el siglo XXI, Revista de Derecho Electoral, $n^{\circ} 7,2009$. 
Pastor Verdú, J.: Democracia, movimientos sociales y crisis de representación política. En Éxodo, nº 89, 2007.

Pastor Yuste, R., Iglesias Onofrio, M.: La dimensión simbólica de la representación política en el Parlamento español, Revista española de ciencia política, $\mathrm{n}^{\circ} 35$, 2014, pp. 91-112.

PÉrez Escalona, S.: Sentencia de 12 de septiembre de 2011. Libertad de admisión en partidos políticos y derecho fundamental de asociación. Cuadernos Civitas de Jurisprudencia Civil, $\mathrm{n}^{\circ}$ 89, 2012.

PÉreZ SÁnCHEZ, M.C.: Concepto de representación política y sistemas electorales proporcionales. Anuario de la Facultad de Derecho de Ourense, nº 1, 2006.

PildES, R.H.: Democracia y representación de intereses minoritarios. En Fundamentos: Cuadernos monográficos de teoría del estado, derecho público e historia constitucional, no 3, 2004 (Ejemplar dedicado a: La Representación Política).

PORRAS RAMIREZ, J.M.: Los partidos políticos como instrumentos al servicio de la formación y expresión de la voluntad popular. Constitución y democracia, 1, 2005.

Portero Molino, J.A.: Sobre la presunción de la representación política. Corts: Anuario de derecho parlamentario, $\mathrm{n}^{\circ} 21,2009$.

Presno Linera, M.A.: ¿Nos representan o no? Anales de la Cátedra Francisco Suárez, $\mathrm{n}^{\circ} 46,2012$.

- La representación política como derecho fundamental. En Fundamentos: Cuadernos monográficos de teoría del estado, derecho público e historia constitucional, $\mathrm{n}^{\circ}$ 3, 2004 (Ejemplar dedicado a: La Representación Política).

- Sistema de gobierno y partidos políticos: de Locke a Park. Revista de estudios políticos, n ${ }^{\circ} 121,2003$.

Rodríguez Blanco, V.: El protagonismo de los partidos en el sistema político: algunas reflexiones y propuesta. Revista General de Derecho Procesal, no 29, 2013.

Rodríguez López, A.: Análisis de la evolución de los partidos políticos contemporáneos: de los partidos de notables a los partidos electorales-profesionales. Actualidad Administrativa, $\mathrm{n}^{\circ}$ 11, 2012.

- El rol institucional de los partidos políticos en las democracias occidentales. Actualidad Administrativa, $\mathrm{n}^{\circ}$ 10, 2013.

- La relevancia de las funciones sociales de los partidos políticos en el ámbito democrático contemporáneo. Actualidad Administrativa, no 4, 2013.

Rosanvallon, P.: Democracia y desconfianza. Revista de Estudios Políticos, no 134 , Octubre/Diciembre 2006.

SÁNCHEZ LóPEZ, F.: Cámaras diferentes, partidos iguales: los partidos políticos en los bicameralismos de Iberoamérica. América Latina Hoy: Revista de Ciencias Sociales (Salamanca). Vol. 38, Dic. 2004.

SÁnCHez MuÑoz, O.: Partidos políticos y problemas actuales de la democracia representativa, Vol. 6, n 3 (Outubro-Dezembro), 2014

SÁNCHEZ-BEAto LACASA, F.: La representación política durante el siglo XIX en Gran Bretaña. En Política y sociedad, Vol. 48, no 1, 2011.

SAUQuillo GonZÁlez, J.: Confianza y autoridad en la representación política moderna. Anales de la Cátedra Francisco Suárez, n 46, 2012.

- Los fundamentos de la representación política: el origen de la relación conceptual entre pueblo, órgano y ley. Anuario de la Facultad de Derecho de la Universi- 
dad Autónoma de Madrid, nº 8, 2004 (Ejemplar dedicado a: La representación en el derecho).

Sermeño, A.: Democracia y participación política: los retos del presente. En Andamios: revista de investigación social, $\mathrm{n}^{\circ}$ 4, 2006.

Soriano, R.; Alarcón, C.: «Las Elecciones en España: ¿Votos Iguales y Libres?» Revista de Estudios Políticos (nueva época), n ${ }^{\circ}$ 114, 2001.

SuÁREZ-Í̃̃̃guEZ, E.: La verdadera democracia. Las características indispensables. Revista de Estudios Políticos, no 127, Enero/Marzo 2005.

URDÁNOZ, J.: La representación proporcional: génesis histórica de un paradigma confuso. Revista de Estudios Políticos, nº 145, Julio/Septiembre 2009.

VÉrge, T.: Modelos alternativos de participación ciudadana en los partidos políticos españoles: un estudio del PSOE, el PP e IU. Revista española de ciencia política, $\mathrm{n}^{\circ} 17,2007$.

Vírgala Foruria, E.: «Crisis de la representación y democracia directa en España», Asamblea. Revista Parlamentaria de la Asamblea de Madrid, nº 29 (2013).

\section{PROHIBICIÓN Y DISOLUCIÓN DE PARTIDOS POLÍTICOS}

\section{Libros y Capítulos de Libros}

Álvarez Álvarez, L.: «Lealtad constitucional y partidos políticos» en LÓPEz GUERRA, L. y E. Espín Templado (coords.): Actas del I Congreso de la Asociación de Constitucionalistas de España Ed. Tirant lo Blanch, Valencia, 2004.

Asensi Sabater, J.: «Principales dudas acerca de la Ley de Partidos (LO 6/2002 y STC 48/2003)», en AAVV La probibición de partidos políticos, Ed. Universidad de Almería, 2004 .

Barrero Ortega, A.: «Reapertura del debate democracia abierta v. democracia militante en la jurisprudencia del Tribunal Europeo de Derechos Humanos», en Montilla Martos, J. A.: La probibición de partidos, Ed. Universidad de Almería, Almería 2004.

Bastida Freijedo, Francisco J.: «De las defensas y aperturas de la Constitución, en La Defensa del Estado. Actas del I Congreso de la Asociación de Constitucionalistas de España, Tirant lo Blanch, 2004.

Bautista Plaza, D.: La función constitucional de los partidos políticos Ed. Comares. Grana$\mathrm{da}, 2006$.

Blanco Valdés, R. L.: «La nueva Ley de Partidos y la defensa del Estado en López Guerra, Luis y Espin Templado, Eduardo: La defensa del Estado, Ed. Tirant lo Blanch, Valencia, 2004.

- :Suspensión y disolución de los partidos» en Temas Básicos de derecho Constitucional. Aragón Reyes, M. (coord.), Ed. Civitas. Madrid, 2001.

Canitano, E.: El método democrático como límite del derecho de asociación en partidos políticos en la constitución italiana. La probibición de partidos, Ed. Universidad de Almería, Almería 2004.

Catalá i Bas, A.: El respaldo del TEDH a la Ley Orgánica de Partidos Políticos. En el reconocimiento de las víctimas del terrorismo a través de la legislación y la jurisprudencia/coord. por Alexandre H. Catalá i Bas, Fernando García Mengual, 2013. 
Corcuera Atienza, J.; Tajadura Tejada, J.; Virgala Foruria, E.: La ilegalización de partidos políticos en las democracias occidentales. Madrid, Dykinson, 2008.

Denninger, E.: «Democracia militante y defensa de la Constitución» en BendA, MAIHofer, Vogel, Hesse y Heyde: Manual de Derecho Constitucional. Ed. Marcial Pons, Madrid, 2001.

Echarri Casi, F.J.: Disolución y suspensión judicial de partidos politicos, Ed. Dykinson, Madrid, 2003.

Esparza Oroz, M.A.: La ilegalización de Batasuna. El nuevo régimen jurídico de los partidos políticos, Ed. Aranzadi, 2004.

Fernández De Casadevante, C.: El derecho de la democracia a defenderse: la ilegalización de partidos políticos. En soberanía del Estado y derecho internacional: homenaje al profesor Juan Antonio Carrillo Salcedo/coord. por Marina Vargas Gómez-Urrutia, Ana Salinas de Frías, Vol. 1, 2005.

Fernández Hernández, A.: Ley de partidos políticos y derecho penal: una nueva perspectiva en la lucha contra el terrorismo. Valencia, Tirant lo Blanch, 2008.

Fernández SEgado, F.: Algunas reflexiones sobre la Ley Orgánica 6/2002, de partidos políticos, al hilo de su interpretación por el Tribunal Constitucional. En Constitución, estado de las autonomías y justicia constitucional: (libro homenaje al profesor Gurmesindo Trujillo)/coord. por Luis Aguiar de Luque, 2005.

Ferreiro BaAmonde, X.: El proceso de disolución de partidos políticos, Madrid, Iustel 2008. GARBERI LlOBREgAT, J.: Ley de enjuiciamiento civil y legislación complementaria: incluye la Ley Orgánica del Poder Judicial y la regulación del nuevo proceso civil de ilegalización de partidos políticos, Barcelona, Ariel, 2002.

Herreros López, J. M.: «Ilegalización y disolución de partidos», La probibición de partidos, Montilla Martos, José Antonio (dir.): Ed. Universidad de Almería, 2004.

Hinarejos Parga, A.: La prohibición de partidos políticos como mecanismo de defensa del Estado, La Defensa del Estado, Ed. Tirant lo Blanch, Valencia, 2004.

IgLEsIAs BÁREZ, M.: Derechos de asociación y participación políticas y prohibición de partidos: el caso español, en Terrorismo y Derecho bajo la estela del 11 de septiembre, Tirant lo Blanch, 2014.

- La Ilegalización de Partidos Políticos en el Ordenamiento Jurídico Español. Comares, Granada, 2008.

López Guerra, L. y E. Espín Templado (coords.): Ed. Tirant lo Blanch, Valencia, 2004.

López Guerra, L.M.; Espín Templado, Eduardo (coords.): La Defensa del Estado. Actas del I Congreso de la Asociación de Constitucionalistas de España, Ed. Tirant lo Blanch, Valencia, 2004.

Marco Marco, J.J.: El pluralismo político y sus límites: la ley de partidos políticos. En Pluralismo: perspectivas políticas y desarrollos normativos, 2004.

Martínez Ruano, P.: «La prohibición de partidos políticos: un debate abierto», en $L a$ probibición de partidos politicos, Montilla Martos, J. A. (ed.): Ed. Universidad de Almería, 2004.

Martínez Sospedra, M.: Sobre los defectos de la Ley Orgánica de partidos políticos: la ilegalización de Batasuna y el Parlamento Vasco. Homenaje a D. Íñigo Cavero Lataillade/coor. Por José Peña González, 2005. 
Michavila NúÑez, J.M.; Villarino Marzo, J.: STC 48/2003, de 12 de marzo: La constitucionalidad de la Ley Orgánica de Partidos Políticos. Veinticinco años de jurisprudencia constitucional: 25 sentencias fundamentales comentadas/coord. por Alberto Dorrego de Carlos; Luis Martí Mingarro (pr), 2007.

Montalvo Jäskeläınen, F.: El control constitucional de los partidos políticos. En Estado y Comunidades Autónomas en España: sistemas electorales y participación política/coord. por María Isabel Álvarez Vélez, María Fuencisla Alcón Yustas, 2011, pp. 143-206.

Montilla Martos, J.A. (ed.): La probibición de partidos políticos, Ed. Universidad de Almería, Almería 2004.

- : «Presentación. Una Ley para ilegalizar Batasuna», en Montilla Martos (ed.), La probibición de partidos políticos, Ed. Universidad de Almería, Almería 2004.

MorloK, M.: «La prohibición de partidos en Alemania», en Montilla Martos, J. A. (dir.): La probibición de partidos políticos, Universidad de Almería, Almería, 2004.

Navot, S.: «Prohibición de partidos políticos en Israel: crónica de una democracia «a la defensiva», en La probibición de partidos políticos, Montilla Martos, J. A. (dir.): Ed. Universidad de Almería, Almería 2004.

PÉrez-Moneo Agapito, M.: La disolución de partidos politicos por actividades antidemocráticas. Valladolid, Lex Nova, 2007.

: Límites al ejercicio del derecho de creación de partidos políticos: ¡respeta España la jurisprudencia europea?. En el Tribunal de Estrasburgo en el espacio judicial europeo/coord. por Argelia Queralt Jiménez, 2013, pp. 257-288.

Portero Molina, J. A.: «Fundamentos y secuelas de la prohibición de partidos políticos» en Montilla Martos, José Antonio (ed.): La probibición de partidos políticos... Ed. Universidad de Almería 2004.

Rodríguez CoArasa, C.: La disolución judicial de los partidos políticos en el ordenamiento español. En Constitución y democracia: ayer y hoy: libro homenaje a Antonio Torres del Moral, Vol. 2, 2012, pp. 1949-1970.

RodríGuez DíAz, Á.: «La declaración de inconstitucionalidad del Partido «Batasuna» y la Convención Europea de Derechos Humanos», en La probibición de partidos políticos, José Antonio Montilla Martos (dir.): Ed. Universidad de Almería. Almería, 2004.

Rodriguez, A.: La declaración de inconstitucionalidad del partido Batasuna y la Convención Europea de Derechos Humanos. La probibición de partidos, Ed. Universidad de Almería, Almería 2004.

Rodríguez-Vergara Díaz, Á.: «La declaración de inconstitucionalidad del Partido «Batasuna» y la Convención Europea de Derechos Humanos», en La probibición de partidos políticos, Montilla Martos, José Antonio (ed.): Ed. Universidad de Almería, Almería, 2004.

Tajadura Tejada, J.: La doctrina del Tribunal Europeo de Derechos Humanos sobre la prohibición de partidos políticos. México, Universidad Autónoma de México, 2008. - La reforma electoral y la ilegalización de partidos políticos: comentario de la LO 3/2011, de 28 de enero, por la que se modifica la LO 5/1985, de 19 de junio, de régimen electoral general. En estudios sobre la reforma de la Ley Orgánica del Régimen Electoral General: la reforma contínua y discontínua/coord. por Enrique Álvarez Conde, Alicia López de los Mozos Díaz-Madroñero, Francisco Javier Sanjuán Andrés, 2011, pp. 247-278. 
: Partidos políticos y Constitución. Un estudio de la LO 6/2002 de 27 de junio, de Partidos Políticos y de la STC 48/2003, de 12 de marzo, Ed. Cuadernos Civitas, Madrid, 2004.

Torres Del Moral, A.: La Ley 6/2002, de 27 de junio, de Partidos Políticos, y la STC 48/2003, de 12 de marzo: sobre su constitucionalidad. En Gobierno y Constitución: Actas del II Congreso de la Asociación de Constitucionalistas de España/coord. por Pablo Lucas Murillo de la Cueva, 2005.

Vírgala Foruria, E.: «Los límites constitucionales a los partidos políticos en la Ley 6/2002», en La probibición de partidos políticos, Montilla Martos, J. A. (ed.): Ed. Universidad de Almería, Almería, 2004.

—- Los límites constitucionales a los partidos políticos en la LO 6/2002. La probibición de partidos, Ed. Universidad de Almería, Almería 2004.

- : Lucha antiterrorista e ilegalización de partidos políticos. En el reconocimiento de las víctimas del terrorismo a través de la legislación y la jurisprudencia/coord. por Alexandre H. Catalá i Bas, Fernando García Mengual, 2013, ISBN 978-84931442-9-6, pp. 303-349.

Yanes Castaño, A.: Mandato representativo e ilegalización de partido político. Parlamento y diputado/coord. por Francesc Pau i Vall, 2011, pp. 235-248.

\section{Artículos de Revistas}

Aguiar De Luque, L.: Voto particular al Informe del Consejo General de Poder Judicial de 16 de abril de 2002, relativo al anteproyecto de la Ley Orgánica de Partidos Políticos Documentación preparada para la tramitación del Proyecto de Ley Orgánica de Partidos Políticos BOCG, Congreso de los Diputados, Serie A, $n^{\circ} 93-1$, de 24 de abril de 2002.

Aláez Corral, B.: en "Libertad de expresión e ilegalización de partidos políticos», Repertorio Aranzadi del Tribunal Constitucional, Tomo III, sep-dic 2002.

Aliste Santos, T.J.: La peligrosa acogida de la «valoración en conjunto» en la motivación judicial de las resoluciones de ilegalización de los partidos políticos. Diario La Ley, $\mathrm{n}^{\circ}$ 7495, 2010.

Allúe Buiza, Á.: «Pluralismo político en Turquía y el TEDH», Revista de Estudios Europeos, $\mathrm{n}^{\circ} 34.2003$.

Álvarez Álvarez, L.: Lealtad constitucional y partidos políticos. Teoría y Realidad Constitucional, $\mathrm{n}^{\circ}$ 10-11, 2002-2003.

Alvarez Conde, E.: El XXV Aniversario de la Constitución de 1978. Algunas consideraciones sobre la Ley Orgánica 6/2002, de 27 de junio, de partidos políticos. Revista valenciana d'etudis autonòmics, 2003 (Ejemplar dedicado a XXV Aniversario de la Constitución Española).

Álvarez Conde, E.; Catalá i Bas, A. H.: «Los efectos directos y colaterales de la disolución de Herri Batasuna», en Foro, Nueva Época, no 2, 2005.

— : «La aplicación de la ley Orgánica de Partidos Políticos. Crónica inacabada de la ilegalización de Herri Batasuna, Batasuna y EuskalHerritarrok», en Foro, Nueva Época, $\mathrm{n}^{\circ}$ 00/2004. 
Amnistía Internacional. Comentario de la Sección Española de Amnistía Internacional al Proyecto de Ley Orgánica de partidos político de 31 de mayo de 2002 en www.constitucion.rediris.es

Antonio Montilla, J.: «Algunos Cambios en la Concepción de los Partidos. Comentarios a la STC 48/2003, sobre la Ley Orgánica 6/2002, de Partidos Políticos». Teoría y Realidad Constitucional, $\mathrm{n}^{\circ}$ 12-13, UNED, 2004.

Bal Francés, E.: Análisis de las sentencias de la Sala Especial del artículo 61 de la Ley orgánica del oder judicial que han aplicado las previsiones de la Ley orgánica de partidos políticos respecto a la ilegalización política. Estudios jurídicos, no 2004, 2004.

Bastida Freijedo, F. J.: Informe sobre el borrador de la Ley Orgánica de Partidos Políticos. Debates constitucionales, $n^{\circ} 5,2003$. Y en www.constitucion.rediris.es

Benito Langa, J.: Medidas contra la ilegalización de partidos políticos. En La Administración práctica: enciclopedia de administración municipal, ISSN 0210-2781, $\mathrm{n}^{\mathrm{o}} 3,2011$.

Bilbao Ubillos, J.M.: Guión para el debate sobre la disolución de los grupos parlamentarios vinculados a partidos que han sido ¡legalizados judicialmente. Revista Española de Derecho Constitucional, n 68, Mayo/Agosto 2003.

Blanco Valdés, R. L.: «La nueva Ley de Partidos. A propósito de la ilegalización de Batasuna», Revista Claves de Razón práctica, n 124, julio-agosto 2002.

Calderón Cerezo, A.: Algunas consideraciones sobre la aplicación de la Ley de Partidos Políticos: jurisprudencia nacional y del Tribunal Europeo de Derechos Humanos. Revista Española de Derecho Militar, n 93, 2009.

Catalá I Bas, A. H.: «Los Efectos Directos y Colaterales de La Disolución de Herri Batasuna». Foro. Nueva Época. no 2, 2005.

- Las sentencias del Tribunal Constitucional en los casos Bildu y Sortu y el fin de ciclo de la Ley Orgánica de Partidos Políticos. Propuestas de reforma. Teoría y realidad constitucional, $\mathrm{n}^{\circ}$ 31, 2013.

—; Alvarez Conde, E.: La aplicación de la Ley Orgánica de Partidos Políticos: crónica inacabada de la ilegalización de Herri Batasuna, Batasuna y Euskal Herritarrok. Revista de Ciencias Jurídicas y Sociales, no extra 0, 2004.

Dagnino Guerra, A.: El régimen de disolución y suspensión judicial de los partidos políticos en el ordenamiento jurídico español. Revista de Derecho Procesal, $n^{\circ} 1-3$, 2003.

DiAz, A.R.: Batasuna ante el Tribunal Europeo de Derechos Humanos: protección multinivel de derechos en Europa y régimen de los partidos políticos en España. Revista de Derecho comunitario Europeo, v35, n14, 2010.

Díez-Picazo, L.M.: «Sobre la constitucionalidad de la Ley Orgánica de Partidos», Repertorio Aranzadi del Tribunal Constitucional, Tomo III, sep-dic 2002.

Erkoreka Gerbasio, J.I.: Partidos políticos y Derecho fundamental de asociación. Anotaciones críticas a la STC 48/2003, de 12 de marzo. Estudios de Deusto: revista de la Universidad de Deusto, Vol. 51, n 1, 2003.

EsParZa Oroz, M.A.: «Las agrupaciones de electores como forma eventual de sucesión en la actividad de un partido político disuelto», Repertorio Aranzadi del Tribunal Constitucional, Tomo II, primera edición, mayo-agosto 2003.

Espigado Guedes, D.; Cidoncha Martín, A. (dir.): La democracia abierta: ¿El caballo de Troya del régimen democrático? ROED: Revista online de estudiantes de Dere- 
cjp, ISSN-e 2174-1492, no extra 2, 2012 (ejemplar dedicado a: Derecho, democracia y justicia).

Fernández Segado, F.: «Algunas reflexiones sobre la Ley 6/2002, de Partidos Políticos, al hilo de la interpretación del Tribunal Constitucional», Revista de Estudios Políticos (Nueva Época), no 125, jul-sep 2004.

Fernández-Viagas Bartolome, P.: «La prohibición de los partidos políticos contrarios al ordenamiento constitucional», Anuario de Derecho Parlamentario, no 14, 2003.

Ferreiro Bahamonde, X.: Oralidad y escritura en el proceso de disolución de partidos políticos. Oralidad y escritura en un proceso civil eficiente [Coloquio de la Asociación Internacional de Derecho Procesal, 2008]/Federico Carpi (ed. lit.) Manuel Pascual Ortells Ramos (ed. lit.). Vol. 2, 2008.

Figueruelo Burrieza, A.; León Alonso, M.: Límites y garantías del derecho de sufragio pasivo: reflexiones en torno a la Lo 3/2011 de reforma de la Ley Orgánica del régimen electoral general. Corts: Anuario de derecho Parlamentario, no 25, 2011.

GARCÍA GONZÁLEZ, J.: Las causas de disolución y suspensión de un partido político previstas en la Ley Orgánica 6/2002 y su relación con el artículo 515 del Código Penal. Revista del Poder Judicial, no 69, 2003.

García RocA, J.: «La problemática disolución del Partido de la Prosperidad ante el Tribunal Europeo de Derechos Humanos: Estado constitucional y control de las actuaciones de partidos fundamentalistas» en REDC $\mathrm{n}^{\circ}$ 65, 2002.

García Torres Del Moral, A.: «La inconstitucionalidad de los partidos políticos. A propósito de la Ley Orgánica 6/2002 de Partidos Políticos», Revista de Derecho Político, $\mathrm{n}^{\circ}$ 60, 2004.

Glover, H.: Nueva Ley de Partidos Políticos, Iuris: Actualidad y práctica del Derecho, $\mathrm{n}^{\circ} 64,2002$

GonzÁlez Alonso, A.: «La lealtad constitucional. La Constitución como orden de valores o como procedimiento», Revista de Estudios Políticos, n 120, 2003.

GonzÁlez Cueto, T.: «Comentario breve a la Sentencia del Tribunal Constitucional sobre la Ley de Partidos (STC 48/2003, de 12 de marzo)», en Repertorio Aranzadi del Tribunal Constitucional, Tomo III, $\mathrm{n}^{\circ} 2$ mayo-agosto 2003.

Herreros López, J.M.: Ilegalización y disolución de partidos políticos. Boletín Jurídico de la Universidad Europea de Madrid, nº 6, 2003.

Hinarejos Parga, A.: La prohibición de partidos políticos como mecanismo de defensa del Estado. Teoría y Realidad Constitucional, n 10-11, 2002-2003.

- La prohibición de partidos políticos: los casos alemán y español. Revista General Informática de Derecho, $\mathrm{n}^{\circ} 1,2003$.

IgLesias BÁReZ, M.: «El caso Bildu»: continuidad y ruptura en la doctrina del tribunal constitucional sobre la ilegalización de formaciones políticas. Revista Teoría y Realidad Constitucional, Año 2011, $\mathrm{n}^{\circ} 28$.

- : La ley de partidos políticos y el Test de convencionalidad Europeo: el diálogo entre el Tribunal Constitucional y el Tribunal Europeo de Derechos Humanos en torno a la ilegalización de Herri Batasuna y Batasuna. Revista Teoría y Realidad Constitucional, Año 2010, $\mathrm{n}^{\circ} 25$.

- Sentencia del Tribunal Constitucional no 138/2012, de 20 de junio [boe $n^{\circ} 163$, de 9-VII-2012], Ars Iuris Salmanticensis: AIS: Revista Europea e Iberoamericana de Pensamiento y Análisis de Derecho, Ciencia Política y Criminología. 
Informe del Consejo de Estado sobre el Borrador de la L.O. De Partidos Polí́ticos. Debates constitucionales, $\mathrm{n}^{\circ}$ 5, 2003.

Informe del Consejo General del Poder Judicial sobre el Borrador de la L.O. De Partidos Polí́ticos. Debates constitucionales, n ${ }^{\circ}$ 5, 2003.

Í̃̃igueZ, D. y Friedel, S.: «La prohibición de partidos políticos en Alemania», en Claves de la razón práctica, $\mathrm{n}^{\circ}$ 122, 2002.

Lasagabaster Herrarte, I.: El auto del Tribunal Supremo de 30 de marzo de 2011: la ilegalización del partido político Sortu. El Cronista del Estado Social y Democrático de Derecho, $\mathrm{n}^{\circ}$ 20, 2011.

— : La disolución de un partido político y su carácter sancionador. Revista Vasca de Administración Pública. Herri-Arduralaritzako Euskal Aldizkaria, nº 87-88, 2010 (Ejemplar dedicado a: Javier Berriatua in memoriam).

LeOnisio Calvo, R.: Las víctimas del terrorismo en el discurso de los partidos políticos vascos: una aproximación cuantitativa (1980-2011). Revista de Estudios Políticos, $\mathrm{n}^{\mathrm{o}} 161,2013$.

López De Lerma i López, J.: «Comentarios a la Ley de Partidos políticos» La Ley: Revista Jurídica Española de doctrina, jurisprudencia y bibliografía n ${ }^{0}$ 7, 2002.

López Tena, A.: Voto particular al Informe del Consejo General de Poder Judicial de 16 de abril de 2002, relativo al anteproyecto de la Ley Orgánica de Partidos Políticos Documentación preparada para la tramitación del Proyecto de Ley Orgánica de Partidos Políticos BOCG, Congreso de los Diputados, Serie A, no 93-1, de 24 de abril de 2002.

López-Jacoiste Díaz, M.E.: Sentencia del Tribunal Europeo de Derechos Humanos en el caso de Refah Partisi y otros contra Turquía: legítima disolución de un partido político. Anuario Español de Derecho Internacional, n 19, 2003.

Lozano Contreras, F.: El Tribunal Europeo de Derechos Humanos ante la ilegalización de partidos políticos y la anulación de candidaturas en España. Anuario Español de Derecho Internacional, $n^{\circ}$ 25, 2009.

— : La jurisprudencia del Tribunal Europeo de Derechos Humanos en torno a la ilegalización de partidos políticos: el caso de Turquía. Revista Española de Derecho Internacional, $\mathrm{n}^{\circ}$ 2, 2002.

- Las decisiones sobre admisibilidad dictadas por el TEDH con motivo de la ilegalización de determinados partidos políticos y agrupación de electores del País Vasco y Navarra. Revista Española de Derecho Internacional, Vol. 60, nº 1, 2008.

Magdaleno Alegría, A.: Libertad de expresión y partidos políticos en la jurisprudencia del Tribunal Europeo de Derechos Humanos. Anucario da Facultade de Dereito da Universidade de A Coruña, 2007, 11.

Manzanares Samaniego, J.L.: «La disolución de los partidos políticos conforme al Código Penal», Actualidad Penal, 21 de octubre de 2002.

Martín De La Vega, A.: «Los partidos políticos y la Constitución de 1978. Libertad de creación y organización de los partidos en la Ley Orgánica 6/2002», Revista Jurídica de Castilla y León. Número Extraordinario, Enero 2004.

Martínez Garay, L.; Mira Benavent, J.: La responsabilidad penal de las organizaciones terroristas con personalidad jurídica: especial referencia al caso de los partidos políticos. Revista de Derecho Penal, ISSN-e 1698-1189, nº 14, 2010.

MARTín-Retortillo BAQUER, L.: en «El problema de las aspiraciones religiosas con el sistema democrático. ¿Se justifica la disolución de un partido político que las auspi- 
cia? (STEDH «Partido de la Prosperidad y otros c. Turquía», de 31 de julio de 2001)», Revista Española de Derecho Europeo, 2, abril-junio 2002.

- Partidos políticos y conexiones terroristas. Revista de Administración Pública, $\mathrm{n}^{\mathrm{o}} 191,2013$.

Montilla Martos, J.A.: «Algunos cambios en la concepción de partidos. Comentario a la STC 48/2003, sobre la Ley Orgánica 6/2002, de partidos políticos» Revista Teoría y Realidad constitucional, $\mathrm{n}^{\circ}$ 12-13, segundo trimestre 2003-1 $1^{\circ}$ trimestre, 2004.

MuÑoz PÉrez, M.: Jurisprudencia constitucional y del Tribunal Europeo de Derechos Humanos en materia de ilegalización de partidos políticos. Estudios Jurídicos, $\mathrm{n}^{\circ} 2004,2004$.

Nebrera GonZÁlez, M.: «Patriotismo» y mutación constitucionales (En torno a la LO 6/2002 de partidos políticos y la STC 48/2003)», Revista de Estudios Políticos (Nueva Época), no $123,2004$.

Ovejero Puente, A.M.: Los límites al ejercicio de derechos en los partidos políticos, según el Convenio Europeo de Derechos Humanos: comentario a la Sentencia de Ilegalización de HB. Civitas. Revista Española de Derecho Europeo, nº 32, 2009.

Pantoja García, F.: Voto particular al Informe del Consejo General de Poder Judicial de 16 de abril de 2002, relativo al anteproyecto de la Ley Orgánica de Partidos Políticos Documentación preparada para la tramitación del Proyecto de Ley Orgánica de Partidos Políticos BOCG, Congreso de los Diputados, Serie A, $n^{\circ} 93-1$, de 24 de abril de 2002.

Pérez Moneo Agapito, M.: ANV Crónica de una impugnación anunciada, en Revista Española de Derecho Constitucional, no 80, 2007.

Pérez Moneo, A.M.: «AukeraGutziak y la sucesión de Batasuna: un nuevo episodio en la ilegalización de partidos. La Sentencia del Tribunal Supremo de 26 de marzo de 2005 y la STC 68/2005», Revista Española de Derecho Constitucional, nº 74, mayo-agosto 2005.

- : :Parámetros para enjuiciar la continuidad entre partidos ilegalizados y agrupaciones de electores (la conexión entre las Sentencias del Tribunal Supremo de 3 de mayo de 2003 y la STC 85/2003)», Revista Española de Derecho Constitucional, año 24, $\mathrm{n}^{\mathrm{o}} 70$, enero-abril 2004.

PÉrez Sola, N.: La «necesidad social imperiosa» de la disolución de los partidos políticos. A propósito de las Sentencias del Tribunal Europeo de Derechos Humanos en el Asunto Herri Batasuna c. España, Etxeberría y otros c. España y Herritarren Zerrende c. España de 30 de junio de 2009. Revista de Estudios Jurídicos, no 9, 2009.

Porras Ramírez, J.M.: «Comentarios acerca del estatus constitucional de los partidos políticos y de su desarrollo en la Ley Orgánica 6/2002», Revista de las Cortes Generales, $\mathrm{n}^{\circ}$ 57, Madrid, 2002.

Presno Linera, M.A.: «El Tribunal Constitucional como segunda instancia electoral en los amparos interpuestos por las agrupaciones de electores a las que se refiere el art. 44.4 LOREG: la STC 85/2003, de 8 de mayo», en Teoría y Realidad constitucional, $\mathrm{n}^{\text {os }} 12-13,2^{\circ}$ semestre $2003-1^{\circ}$ semestre 2004.

Pulido Quecedo M.: «A vueltas con la nueva Ley de Partidos», en Repertorio Aranzadi del Tribunal Constitucional, Tomo II, mayo-junio, 2002.

- Jurisprudencia. Tribunal Constitucional: Presentación de candidaturas de partidos políticos. Derecho de los Negocios, ISSN-e 2254-9013, Año no 255, 2011. 
Quesada AlCalá, C.: «La «ilegal» ilegalización del Partido comunista en Rumania antesdel ejercicio de sus funciones. Comentario a la sentencia del TEDH, Partidul Comunistilor (Nepeceresti) y Ungureanu c. Roumanie de 3 de febrero de 2005»,en Iustel.com $R G D E, \mathrm{n}^{\circ} 7$, mayo 2005.

: La prohibición de un partido político turco: sentencia del TEDH, Refah Partisi (The Welfare Party) y otros c. Turquía de 13 de febrero de 2002. Revista General de Derecho Europeo, $\mathrm{n}^{\circ}$ 1, 2003.

Revenga SÁnchez, M.: «Trazando los límites de lo tolerable: Libertad de expresión y defensa del ethos democrático en la jurisprudencia constitucional española», Cuadernos de Derecho Público, no 21 (enero-abril, 2004).

- «El tránsito hacia (y la lucha por) la democracia militante en España», Revista de Derecho Político, $\mathrm{n}^{\circ}$ 62, 2005.

Rivero GonzÁlez, M.: Análisis doctrinal de la Ley orgánica 6/2002, de 27 de junio, de partidos políticos. Estudios jurídicos, n $2004,2004$.

Rodriguez, A.: Tribunal Europeo de Derechos Humanos. Batasuna ante el Tribunal Europeo de Derecho Humanos: protección «multinivel» de derechos en Europa y régimen de los partidos políticos en España. Revista de Derecho Comunitario Europeo, Año no $14, \mathrm{n}^{\circ} 35,2010$.

Rodríguez-Zapata Pérez, J.: «Partidos Políticos y Democracia Combativa». Revista Valenciana D'estudis Autonomics. $\mathrm{n}^{\circ}$ 39-40, 2003. p. 122-135.

SaIz ArnaIz, A.: «La disolución de los partidos políticos y el derecho de asociación: el test de convencionalidad (art. 11 CEDH)», en Actualidad Jurídica Aranzadi, n 533, 2002.

SAlazar Benítez, O.: La dudosa constitucionalidad de las limitaciones del derecho de sufragio pasivo previstas por L.O. 6/2002, de Partidos Políticos. Comentario a las SSTS de 3 de mayo y a la STC 85/2003 de 8 de mayo. Revista de Estudios Políticos, $\mathrm{n}^{\circ} 122$, Octubre/Diciembre 2003.

SÁnchez Ferro, S.: «El complejo régimen jurídico aplicable a los partidos tras la aparición de la Ley Orgánica de Partidos Políticos de 27 de junio de 2002», en Revista Jurídica. Universidad Autónoma de Madrid, $\mathrm{n}^{\circ}$ 12, 2005.

Santaolalla López, F.: Parlamento y persecución del delito. Comentario sobre los incidentes producidos en el Parlamento vasco por la suspensión de un grupo parlamentario por un auto judicial. Revista Española de Derecho Constitucional, $\mathrm{n}^{\circ} 68$, Mayo/Agosto 2003.

Serrano Maillo, I.: «Agrupaciones de electores y la posible continuidad de partidos políticos ilegalizados por parte de éstas (Comentario a la STC 68/2005, de 31 de marzo)», Teoría y Realidad constitucional, $\mathrm{n}^{\circ}$ 16, UNED, 2005.

Tajadura Tejada, J.: «La dimensión externa del principio de constitucionalidad de los partidos políticos en el ordenamiento jurídico español», Revista Teoría y Realidad constitucional, $\mathrm{n}^{\text {os }} 12-13,2003-2004$.

— : El caso Bildu: un supuesto de extralimitación de funciones del Tribunal Constitucional. Revista Española de Derecho Constitucional, n 93 , Septiembre/Diciembre 2011 .

- L La doctrina del Tribunal Europeo de Derechos Humanos sobre la prohibición de partidos políticos. Revista Jurídica de Navarra, n 44, 2007. 
La Sentencia del Tribunal Constitucional de 20 de junio de 2012 y el debilitamiento de la eficacia de la Ley Orgánica de Partidos Políticos. Revista Española de Derecho Constitucional, nº 98, Mayo/Agosto 2013.

Torres Del Moral, A.: La inconstitucionalidad de los partidos: a propósito de la Ley 6/2002 de Partidos Políticos. Revista de Derecho Político, nº 60, 2004.

Vírgala Foruria, E.: «Comentario a La STS de 27 de marzo de 2003 de ilegalización de Batasuna: El Estado de Derecho penetra en Euskadi», Revista Teoría y Realidad Constitucional, núms. 12-13, segundo semestre 2003-primer semestre 2004.

: «El cerco judicial a los partidos con vínculos terroristas: de la STC 48/2003 al ATS de 18 de junio de 2003», en Jueces y Democracia, 2004.

- : «La STS de 27 de marzo de 2003 de ilegalización de Batasuna: El Estado de Derecho penetra en Euskadi», Revista Teoría y Realidad Constitucional, $\mathrm{n}^{\text {os }} 12-13$; segundo semestre 2003-primer semestre.

- :Los partidos políticos ilícitos tras la LO 6/2002», en Teoría y Realidad constitucional, $\mathrm{n}^{\mathrm{o}} 10-11,2003$.

- La admisión de iniciativa internacionalista a las elecciones europeas de 2009: el Tribunal Constitucional corrige acertadamente la decisión del Tribunal Supremo. Revista Española de Derecho Constitucional, no 87, Septiembre/Diciembre 2009.

- Las sentencias del TS y del TC de mayo de 2011 sobre Bildu y las Agrupaciones electorales. Revista Española de Derecho Constitucional, n 93, Septiembre/Diciembre 2011.

-: STC 138/2012, de 20 de junio, sobre constitución de Sortu: la ¿definitiva? legalización de la Izquierda Abertzale. Revista Española de Derecho Constitucional, $\mathrm{n}^{\circ}$ 96, Septiembre/Diciembre 2012.

\section{FINANCIACIÓN DE PARTIDOS POLÍTICOS}

\section{Libros y Capítulos de Libros}

Ariño Ortiz, G.: La financiación de los partidos políticos. Madrid, Ediciones CINCA, 2009.

Blanco Valdés, R. L.: «Financiación de los Partidos». Aragón Reyes, M. (coord.): Temas Básicos de Derecho Constitucional - Tomo I. Derecho Constitucional y Fuentes de Derecho. Civitas, Madrid, 2001.

Castillo Vera, P.: «La Financiación de los Partidos Políticos en España». Castillo, P. Del; Zovatto G., D. (eds.): La Financiación de la Política en Iberoamérica. $1^{\circ}$ ed. IIDH/CAPEL, San José, 1998.

Cataluña Sindicatura de Cuentas: Acuerdo de transparencia y autolimitación de gastos electorales y de financiación de los partidos políticos: ejercicio 2003-2006. Barcelona, Sindicatura de Cuentas de Cataluña, 2010.

- Rendición de cuentas de los partidos políticos y de las asociaciones y fundaciones vinculadas: ejercicios 2010 y 2011, Barcelona, sindicatura de Cuentas de Cataluña, 2013.

- Rendición de cuentas de los partidos políticos y de las asociaciones y fundaciones vinculadas: ejercicios 2012, Barcelona, Sindicatura de Cuentas de Cataluña, 2014. 
Cortes Bureta, P.: «La Financiación de los Partidos Europeos y la Financiación de los Gastos de Seguridad: Últimas Novedades». AA.VV.: Derecho Constitucional para el Siglo XXI — Actas del VIII Congreso Iberoamericano de Derecho Constitucional, Tomo II. Thompson — Aranzadi, Sevilla, 2006.

- Recursos Públicos y Partidos Políticos: Balances y Perspectivas de Reforma. Centro de Estudios Políticos y Constitucionales, Madrid, 2003.

FERNÁNDEZ ViVAs, Y.: Igualdad de oportunidades y financiación de los partidos políticos en Alemania. En Constitución y democracia: 25 años de Constitución democrática en España:(Actas del Congreso celebrado en Bilbao los días 19 a 21 de noviembre de 2003)/coord. por Miguel Angel García Herrera, Vol. I, 2005.

—: Igualdad y Partidos Políticos: Análisis Constitucional y Comparado de la Igualdad de Oportunidades de los Partidos Políticos. Congreso de los Diputados, Madrid, 2007.

Fernández-Llebréz, F.: «La Financiación de los Partidos Políticos: Evolución y Rasgos Principales». VV.AA.: Curso de Partidos Políticos. Akal, Madrid, 2003, pp. 171-196.

García Laguardia, J. M.: «La Financiación Política en América Latina». AA.VV.: Derecho Constitucional para el Siglo XXI - Actas del VIII Congreso Iberoamericano de Derecho Constitucional, Tomo II. Thompson — Aranzadi, Sevilla, 2006.

Gavara De Cara, J. C.: «La Financiación Electoral en el Ámbito Autonómico». Gálvez Muñoz, L. A. (dir.): El Derecho Electoral de las Comunidades Autónomas. Revisión y Mejora. Cuadernos y Debates, Centro de Estudios Constitucionales, Madrid, 2009.

Gómez SÁnCHez, Y.: El Tribunal de Cuentas: El Control Económico - Financiero Externo en el Ordenamiento Constitucional Español. Universidad Nacional de Educación a Distancia. Marcial Pons, Madrid, 2001.

Holgado González, M.: La Financiación de los Partidos Políticos en España. Tirant lo Blanch, Valencia, 2003.

Maroto, M.: Qué hacemos con la financiación de los partidos políticos. Tres Cantos, Madrid, Akal, 2013.

MARTínez Isidoro, B.: Transparencia informativa de los partidos políticos y las fundaciones vinculadas a partidos políticos de España. En Gestión de la escasez: participación, territorios y estado del bienestar: experiencias en democracia y participación/coord. Por Rafael Bañón i Martínez, Rubén Tamboleo García, 2013.

Nieto De Alba, U.: Ética, política, economía y control: el caso de los partidos políticos. Madrid, Ediciones 2010, 2014.

Nieto Martín, A.: Financiación ilegal de partidos políticos (arts. 10-13). En Fraude y corrupción en el Derecho penal económico europeo: eurodelitos de corrupción y fraude/coord. por Luis Alberto Arroyo Zapatero, Adán Nieto Martín, 2006.

Olaizola Nogales, I.: La financiación ilegal de los partidos políticos: un foco de corrupción: una propuesta de regulación penal. Valencia, Tirant lo Blanch, 2014.

Pajares Montolio, E.: «El Tribunal de Cuentas y los Límites del Control de la Financiación de los Partidos Políticos». AA.VV.: Derecho Constitucional para el Siglo XXI - Actas del VIII Congreso Iberoamericano de Derecho Constitucional, Tomo II. Thompson - Aranzadi, Sevilla, 2006.

- El Tribunal de Cuentas y los límites del control de la financiación de los partidos políticos. En Derecho Constitucional para el siglo XXI: actas del VIII Congreso Iberoamericano de Derecho Constitucional. Vol. 2, 2006. 
Perez Francesch, J.L.: La financiación de los partidos políticos en España. Consideraciones a partir de los informes del Tribunal de Cuentas y de la nueva Ley Orgánica 8/2007, de 4 de julio, 2009.

Rodriguez Lopez, A.: Contabilidad y financiación de los partidos políticos, Valencia, CISS, 2011.

—; Fidalgo Cerviño, E.: Contabilidad y Financiación de los Partidos Políticos. CISS, Madrid, 2011.

Romero Flores, B.: Partidos politicos y responsabilidad penal: la financiación electoral irregular, Barcelona Atelier, 2005.

SÁNCHEZ MuÑOZ, O.: «Cuestiones Relativas a la Financiación de los Gastos Electorales y al Desarrollo de Comunicación». AA.VV.: El Informe del Consejo de Estado sobre la Reforma Electoral. CEPC, Madrid, 2009, pp. 617-656.

- La Igualdad de Oportunidades en las Competiciones Electorales. CEPC, Madrid, 2007

TRIBUnAL DE Cuentas: Moción relativa a la modificación de la normativa sobre financiación y fiscalización de los partidos políticos. Madrid, Tribunal de Cuentas, 2001.

- Informe de fiscalización de la contabilidad de los partidos políticos: ejercicio 1999; Informe complementario relativo a la fiscalización de las contabilidades electorales de las elecciones al Parlamento de Cataluña. Tribunal de Cuentas, 2002.

- Informe de fiscalización de la contabilidad de los partidos políticos del ejercicio 1998. Madrid. Tribunal de Cuentas, 2001.

— : Informe de fiscalización de la contabilidad de los partidos políticos del ejercicio 2000. Madrid. Tribunal de Cuentas, 2001.

- Informe de fiscalización de la contabilidad de los partidos políticos del ejercicio 2002. Madrid. Tribunal de Cuentas, 2005.

- Informe de fiscalización de los estados contables del ejercicio 2004 de los partidos políticos con representación parlamentaria en las Cortes Generales o en las Asambleas Legislativas de las Comunidades Autónomas. Madrid, Tribunal de Cuentas, 2008.

—- Informe de fiscalización de los estados contables del ejercicio... de los partidos políticos con representación parlamentaria en las Cortes Generales o en las Asambleas Legislativas de las Comunidades Autónomas. Madrid. Tribunal de Cuentas, 2007.

: Informe de fiscalización sobre la contabilidad de los partidos políticos: ejercicio 2001. Madrid, Tribunal de Cuentas, 2003.

- Informe de fiscalización sobre la contabilidad de los partidos políticos: ejercicio 2000. Madrid, Tribunal de Cuentas, 2003.

- Informe de fiscalización sobre la contabilidad de los partidos políticos: ejercicio 2003. Madrid, Tribunal de Cuentas, 2006.

\section{Artículos de Revistas}

Argandoña, A.: «La Financiación de los Partidos Políticos y la Corrupción en las Empresas». Papeles de Ética, Economía y Dirección, nº 6, [s.1.], 2001.

Artés Caselles, J.; García Viñuela, E.: «La Economía Política de las Reformas de la Financiación Electoral». Revista Española de Ciencia Política, nº 15, 2006. 
Boix Palop, A.: «Sobre la Constitucionalidad de la Reforma de la Financiación de Partidos Políticos: Reparos al carácter convalidador de la misma». Revista General de Derecho Administrativo, $\mathrm{n}^{\circ} 1,2002$.

Cano Silva, R.: El control político del Parlamento de Andalucía de las contabilidades de los Grupos parlamentarios y la financiación de los partidos políticos. Revista de Estudios de la Administración Local y Autonómica, nº 317, 2011.

Coello De Portugal, J.M.: La «Ley Orgánica 5/2012, de 22 de octubre», una buena reforma en una buena dirección del régimen de financiación de los partidos políticos. Foro: Revista de Ciencias Jurídicas y Sociales, Vol. 15, nº 2, 2012.

Cortés Bureta, P.: Los recursos económicos de los partidos políticos: una perspectiva histórica de su regulación. Revista Aragonesa de Administración Pública, no 22, 2003.

- «Los Recursos Económicos de los Partidos Políticos: Una Perspectiva Histórica de su Regulación». Revista Aragonesa de Administración Pública. no 22, 2003.

- Aproximación al concepto de subvención y su adecuación en la Ley 3/1978, de 2 de julio, de Financiación de Partidos Políticos. Cuadernos Constitucionales de la Cátedra Fadrique Furió Ceriol, no 38-39, 2002.

Cubiles SÁnchez-Pobre, P.: La financiación de los partidos políticos. Estudio de su régimen tributario. Civitas. Revista Española de Derecho Administrativo, n ${ }^{\circ}$ 143, 2009.

Cuñado Ausin, G.: «La Fiscalización de los Partidos Políticos: Una Síntesis de las Actuaciones Practicadas por el Tribunal de Cuentas». Revista Española de Control Externo, vol. 3, $\mathrm{n}^{\circ}$ 9, 2001.

Ferreira Rubio, D.: «Financiamento de Partidos e Campanhas: Fundos Públicos versus Fundos Privados». Novos Estudos, n ${ }^{\circ} 73$, nov. CEBRAP, 2005.

García De PaBlos, J.F.: La problemática de la financiación de los partidos políticos. Actualidad Jurídica Aranzadi, nº 859, 2013.

García Maceiras, O.: «Dos Visiones sobre la Financiación Electoral y la Libertad de Expresión de las Corporaciones Privadas: a Propósito de la Sentencia de la Corte Suprema «Citizens United v. Federal Election Commission» y el Voto Particular del Juez Stevens». Dereito. Revista Xurídica da Universidade de Santiago de Compostela. $\mathrm{n}^{\circ} 1$. v. 19, 2010.

García Ortiz, F.: El control del Tribunal y del Parlamento: la fiscalización de los partidos políticos. Revista Española de Control Externo. Vol. 6, n 16.

García Viñuela, E.; GonZÁlez De Aguilar, C.: Financiación de los partidos y búsqueda de rentas: un análisis de las reformas de la financiación política española de 2007 y 2012. Revista Española de Ciencia Política. ISSN 1575-6548, no 34, 2014.

García Viñuela, E.; Vazques Vega, P.; Artés Caselles, J.: «El Gasto Público en Financiación Política: Las Subvenciones para el Funcionamiento Ordinario de los Partidos». Revista de Estudios Políticos, n 128, CEPC, Madrid, 2005.

— ; - «Financiación Pública de los Partidos y Cartelización de la Oferta Política». Revista Española de Ciencia Política. no 20, abril, Cyan, Madrid, 2009.

- - - : «La Regulación del Dinero Público». Revista Española de Investigaciones Sociológicas - REIS, n ${ }^{\circ}$ 118, CIS, Madrid, 2007, pp. 65-95.

—; - - Artés CASElles, J.: «La Financiación de las Elecciones Generales en España, 1977-2000». Documentos — Universidad Complutense de Madrid. Instituto de Estudios Fiscales, no 24, Madrid, 2004. 
Gil Castellano, J.: «La Financiación de los Partidos Políticos: El Estado de la Cuestión». Cuadernos Constitucionales de la Cátedra Fadrique Furió Ceriol, n 36/37, Valencia, 2001.

Holgado González, M.: «Financiación de Partidos y Democracia Paritaria». Revista de Estudios Políticos, $\mathrm{n}^{\circ}$ 115. CEPC, Madrid, 2002.

IgLESIAs BÁREZ, M.: Ley Orgánica 5/2012, de 22 de octubre, de reforma de la Ley Orgánica 8/2007, de 4 de julio [BOE $n^{\circ}$ 255, 23-X-2012]. Ars Iuris Salmanticensis: AIS: Revista Europea e Iberoamericana de Pensamiento y Análisis de Derecho, Ciencia Política y Criminología, ISSN-e 2340-5155, Vol. 1, nº 1, 2013, pp. 172-174. La Ley Orgánica 5/2012, de 22 de Octubre, de Reforma de la Ley Orgánica 8/2007, de 4 de julio. Financiación de partidos políticos: continuidad y ruptura en el sistema español.

INFORME de la Dirección General de Cooperación Local sobre distintas cuestiones en relación a la dotación económica a los grupos políticos municipales y la Ley 8/2007, de 4 de julio, sobre financiación de los partidos políticos. Consultor de los ayuntamientos y de los juzgados: Revista técnica especializada en administración local y justicia municipal, $\mathrm{n}^{\circ} 13,2008$.

Lopez De La Fuente, G.: La novedosa propuesta de reglamento sobre el estatuto y la financiación de los partidos políticos europeos y las fundaciones políticas europeas. Revista de Derecho de la Unión Europea, n 26, 2014.

Martínez Cuevas, M.D.: Comentario al reglamento (CE) no 2004/2003 del Parlamento Europeo y del Consejo, de 4 de noviembre de 2003, relativo al Estatuto y la Financiación de los partidos políticos a escala europea. Revista de Derecho Constitucional Europeo, no 3, 2005.

- La financiación de los partidos políticos en el ordenamiento jurídico español. Algunas consideraciones de derecho comparado. Revista de la Facultad de Derecho de la Universidad de Granada, n ${ }^{\circ}$ 8, 2005.

Mirón Ortega, M. A.: «Subvenciones y Contabilidad de los Grupos Parlamentarios». Corts - Anuario de Derecho Parlamentario. n ${ }^{\circ}$ 10, Valencia, 2001.

MuÑoz, O.S.: La financiación de los partidos políticos en España: Ideas para un debate. Revista Española de Derecho Constitucional, v33 n99, 2013.

NúÑez PÉrez, M.: La financiación de los partidos políticos. Revista Española de Control Externo, Vol. 11, n 33, 2009.

Pajares Montolio, E.: «La Financiación y la Campaña Electoral en los Regímenes Electorales Autonómicos». Cuadernos de Derecho Público. no 22-23. Madrid, 2004.

Pérez Francesch, J. L.: «La Financiación de los Partidos Políticos en España. Consideraciones a Partir de los Informes del Tribunal de Cuentas y de la Nueva Ley Orgánica 8/2007, de 4 de julio». Papers — Revista de Sociología. no 92, UAB, Barcelona, 2009.

Presno Linera, M.A.: Supresión, como recursos de partidos políticos de las subvenciones recibidas por los grupos parlamentarios. Debates constitucionales, $\mathrm{n}^{\circ}$ 6, 2004

Rey Martínez, F.; Martí Gómez, J.; Bilbao, J.M.; Foix, L.; Perez Alcalá, G.; Lopez Burniol, J.J.: Los partidos políticos gastan demasiado dinero. El Ciervo, v55, n658.

Rivero Ortiz, R.: Financiación de los partidos políticos: tipificación penal de los actos de sobrecogimiento (de sobres), Diario La Ley, nº 8080, 2013.

Rodríguez López, A.: Análisis de las modalidades de financiación pública directa de los partidos políticos. Actualidad Administrativa, no 21-22, 2012. 
: El impuesto de partido como vía de financiación pública indirecta en el sistema político. Actualidad Administrativa, n ${ }^{\circ}$ 11, 2014.

- La financiación de la actividad ordinaria de los partidos políticos en la legislación española. Actualidad Administrativa, nº 13, 2010.

- Los recursos financieros privados internos en el ámbito de la política. Actualidad Administrativa, $\mathrm{n}^{\circ}$ 1, 2014.

- Ventajas e inconvenientes de la financiación pública de los partidos políticos. Actualidad Administrativa, no 18, 2011.

- Fidalgo Cerviño, E.: «La Necesidad de un Modelo Contable Normalizado para los Partidos Políticos en España: ¿De la Utopía a la Realidad?» AECA: Revista de la Asociación Española de Contabilidad y Administración de Empresas. no 86. [s.l.], 2009.

—; - «La Financiación de la Actividad Ordinaria de los Partidos Políticos en la Legislación Española». Actualidad Administrativa. tomo 2. n 13. La Ley, 2010.

- - - «Subvenciones, Donaciones y Legados a los Partidos Políticos desde la Perspectiva del PGC 2007». Partida Doble. n 221, mayo, Madrid, 2010.

Samaniego Riaño, P.: «Las Subvenciones Electorales». Anuario Jurídico de La Rioja. $\mathrm{n}^{\mathrm{o}} 11$, Logroño, 2006.

SÁnCHez Ferro, S.: Las subvenciones condicionadas en el Estado autonómico. Revista General de Derecho Constitucional, n ${ }^{\circ} 11,2011$.

SÁNCHEZ MuÑOZ, O.: La financiación de los partidos políticos en España: ideas para un debate. Revista Española de Derecho Constitucional, n 99, Septiembre/Diciembre 2013.

— : La regulación de la competición electoral en Canadá: un modelo igualitario. Revista de Estudios Políticos, n 162, Octubre/Diciembre 2013.

SÁnchez-Pobre, P. C.: «La Financiación de los Partidos Políticos: Estudio de su Régimen Tributario». Revista Española de Derecho Financiero Civitas. n 143 , Aranzadi, Navarra, 2009.

SAntano, A.C.: La financiación ordinaria de los partidos políticos en España. Nuevas normas, viejos desafíos. The financing of spanish political parties - new rules, old challeng Revista General de Derecho Constitucional, n 19, 2014.

Serrano Maíllo, M. I.: «La Financiación de los Partidos Políticos en España». Teoría y Realidad Constitucional. n ${ }^{\circ} 12-13$, UNED, Madrid, 2004.

Serrano Ruiz, E.: «Régimen Jurídico de la Financiación de los Grupos Parlamentarios. Las Subvenciones, la Cesión de Locales y de Medios Materiales». Asamblea: Revista Parlamentaria de la Asamblea de Madrid. no extraordinario, Madrid, 2007.

UlloA, F.: Aplicación efectiva de las normas de financiación y sanciones de los partidos políticos. Revista de Derecho Político, nº 67, 2006.

Zovatto, D.: Dinero y política en América Latina. Revista de Derecho Electoral, ISSN-e 1659-2069, n' $2,2006$.

\section{DEMOCRACIA PARITARIA Y CUOTAS ELECTORALES}

\section{Libros y Capítulos de Libros}

Aguado, A.M.: Construcción de la ciudadanía, género y culturas políticas. De la democracia ateniense a la democracia paritaria/coord. por María Pilar Pérez Cantó, 2009. 
ApONTE SÁNCHEZ, E.R.: Las mujeres en la democracia participativa y protagónica de la revolución bolivariana de Venezuela. En Democracia paritaria: aportaciones para un debate/coord. por Ángela del Carmen Sierra González, María del Pino de la Nuez Ruiz, 2007.

Aranda Álvarez, E.: Democracia paritaria. Un estudio crítico. Madrid, Centro de Estudios Políticos y Constitucionales, 2013.

: Discriminación por razón de sexo en el ámbito político: los problemas de las cuotas electorales. En Derecho constitucional para el siglo XXI: actas del VIII Congreso Iberoamericano de Derecho Constitucional/coord. por Manuel Carrasco Durán, Francisco Javier Pérez Royo, Joaquín Urías Martínez, Manuel José Terol Becerra, Vol. 1, 2006, pp. 771-796.

Biglino Campos, M.P.: Las mujeres en los partidos políticos: representación, igualdad y cuotas internas. Mujer y Constitución en España, 2000.

- Reforma de los Estatutos de autonomía y democracia paritaria. En Género, constitución y estatutos de autonomía/coord. por Teresa Freixes Sanjuán, Julia Sevilla Merino, 2005.

Cantarino Suñer, E.; Mertens De Wilmars, F.: Ciudadanía paritaria. Nuevos retos para la democracia liberal igualitaria. En Ética, ciudadanía y desarrollo/coord. por Agustín Domingo Moratalla, Juan Francisco Lisón Buendía, 2008.

Coвo Bedía, R.: Debates teóricos sobre democracia paritaria. En Nuevas rutas para Clío: el impacto de las teóricas francesas en la historiografía feminista española/ coord. por Gloria Angeles Franco Rubio, Ana Iriarte Goñi, 2009.

— Identidad política feminista y democracia paritaria. En Radicalizar la democracia: sociedad civil, movimientos sociales e identidad religiosa/coord. por José Antonio Zamora Zaragoza; Foro «Ignacio Ellacuría» Solidaridad y Cristianismo (dir. congr.), 2001.

Femenías, M.L.: Cuotas, ¿un camino hacia la paridad? En Democracia paritaria: aportaciones para un debate/coord. por Ángela del Carmen Sierra González, María del Pino de la Nuez Ruiz, 2007.

Figueruelo Burrieza, A.: Representación política, derecho de asociación y democracia paritaria. En Nuevas tecnologías, administración y participación ciudadana/coord. por Zulima Sánchez Sánchez, 2010.

Franco Rubio, G.A.: De la vida doméstica a la presencia pública: las muejeres en las cortes franquistas. En De la democracia ateniense a la democracia paritaria/coord. por María Pilar Pérez Cantó, 2009.

Frax Rosales, E.; Matilla Quiza, M.: Socialismo y sufraguismo en el primer tercio del siglo XX: la agrupación femenina socialistas. En De la democracia ateniense a la democracia paritaria/coord. por María Pilar Pérez Cantó, 2009.

García-Mercadal y García-Loygorri, F.: La presencia de la mujer en la vida política y parlamentaria española: de la conquista del voto femenino a la democracia paritaria. Almería: Instituto de Estudios Almerienses, 2005.

González De Chavez Fernández, M.A.: Lo personal es político. En Democracia paritaria: aportaciones para un debate/coord. por Ángela del Carmen Sierra González, María del Pino de la Nuez Ruiz, 2007. 
Guerra Palmero, M.J.: Democracia paritaria e inclusión: reflexiones feministas. En Democracia paritaria: aportaciones para un debate/coord. por Ángela del Carmen Sierra González, María del Pino de la Nuez Ruiz, 2007.

Holgado GonzÁlez, M.: Democracia paritaria y soberanía compartida. En El levantamiento del velo: las mujeres en el derecho privado/coord. por Laura López de la Cruz, Marta Otero Crespo; María Paz García Rubio (dir.), Rosario Valpuesta Fernández (dir.), 2011.

IgLESIAS VilA, M.: La acción positiva en la forma de cuotas electorales rígidas: algunas reflexiones en torno a los casos Coahuila y Veracruz. En Tópicos electorales: un diálogo judicial entre América y Europa/coord. por Luis Efrén Ríos Vega, 2011.

Lazo Fuente, X.: La igualdad de oportunidades y acciones positivas en América Latina: ámbitos de mayor incidencia. En Bioética y feminismo: estudios multidisciplinares de género/coord. por María Teresa López de la Vieja de la Torre, 2006.

Leissner, M.: Las cuotas electorales: apuntes desde la experiencia sueca. En Tópicos electorales: un diálogo judicial entre América y Europa/coord. por Luis Efrén Ríos Vega, 2011.

Macías Jara, M.: Democracia representativa paritaria y ciudadanía. En Género y derecho: luces y sombras en el ordenamiento jurídico español/coord. por María Soledad de la Fuente Núñez de Castro, 2008.

Martín De Llano, M.; Serrano Má́llo, M.: El principio de igualdad y la democracia paritaria. En torno a la igualdad y a la desigualdad/Santiago Sánchez González (aut.), 2009.

Martínez Alarcón, M.L.: Cuota electoral de mujeres y Derecho Constitucional. Congreso de los Diputados, 2007.

Miguel Álvarez, A.: Hacia una sociedad paritaria: la redefinición de lo público y lo privado. En Democracia paritaria: aportaciones para un debate/coord. por Ángela del Carmen Sierra González, María del Pino de la Nuez Ruiz, 2007.

Molina Petit, C.: Democracia paritaria en la representación de intereses. En Democracia paritaria: aportaciones para un debate/coord. por Ángela del Carmen Sierra González, María del Pino de la Nuez Ruiz, 2007.

Naranjo De La Cruz, R.: La constitucionalidad de las medidas de fomento de la participación política de la mujer desde la perspectiva del régimen constitucional de los partidos políticos. XXV Aniversario de la Constitución Española: propuestas de reformas/coord. por María Luisa Balaguer Callejón, 2004.

Navarro Swain, T.: ¿Qué democracia es ésta? Derechos humanos de las mujeres y la diferencia sexual. En Democracia paritaria: aportaciones para un debate/coord. por Ángela del Carmen Sierra González, María del Pino de la Nuez Ruiz, 2007.

Nuez Ruiz, M. DE LA: La paridad: marco legislativo. En Democracia paritaria: aportaciones para un debate/coord. por Ángela del Carmen Sierra González, María del Pino de la Nuez Ruiz, 2007.

OlivetTi, M.: Las cuotas electorales de género en Italia, entre legislación y jurisprudencia. En Tópicos electorales: un diálogo judicial entre América y Europa/coord. por Luis Efrén Ríos Vega, 2011.

PARTIDOS POLÍticos Y PARIDAD: LA ECUACIÓN POSIBLE. Wasingthon D.C. Banco Interamericano de Desarrollo, 2010. 
Pérez Cantó, M. (coord.): De la democracia ateniense a la democracia paritaria. Icaria, 2009.

— : De la democracia ateniense a la democracia paritaria. En La historia de las mujeres: perspectivas actuales/coord. por Cristina Borderías Mondejar, 2009.

Rey BouzA, E.: A representación das mulleres nos partidos políticos: o caso do BNG. A Coruña: Deputación Provincial da Coruña, 2008.

- As mulleres nos partidos políticos: o caso galego. Ferrol, Embora, 2008.

Rodríguez García, M.; Mo Romero, E.: Privilegios sin honor para las defensoras de la patria. En De la democracia ateniense a la democracia paritaria/coord. por María Pilar Pérez Cantó, 2009.

Rodriguez Ruiz, B.; Rubio Marín, R.: La democracia como democracia paritaria. En Derecho, género e igualdad: cambios en las estructuras jurídicas androcéntricas/ coord. por Daniela Heim, Encarna Bodelón González, Vol. 1, 2010.

Rubio CAStro, A.M.: La participación política de las mujeres y la democracia paritaria. Cursos de derechos humanos de Donostia-San Sebastián, Vol. 8, 2007.

Ruiz Miguel, A.: Igualdad, libertad y unidad política: a propósito de las cuotas electorales en México. En Tópicos electorales: un diálogo judicial entre América y Europa/coord. por Luis Efrén Ríos Vega, 2011.

SAlazar Benítez, O.: La igualdad de género como fundamento y límite de una democracia intercultural. En Relaciones interculturales en la diversidad/coord. por Luis Rodríguez García, Antonio Rafael Roldán Tapia, 2013.

- Las cuotas electorales femeninas: una exigencia del principio de igualdad sustancial: contra el monopolio de los púlpitos. Universidad de Córdoba, 2001.

SAldaña Diaz, M.: Derechos humanos y democracia paritaria en las Naciones Unidas. En Jaque a la democracia/coord. por Juan Jesús Mora Molina, 2010.

- Hacia una educación política de la mujer ciudadana: democracia paritaria y participación política. En Orientaciones para una educación no sexista/coord. por Emilia Moreno Sánchez, 2010.

SÁNCHEZ HeRnÁNDEZ, M.F.: Liderazgo político de mujeres: desde la transición hacia la democracia paritaria. Sevilla: Instituto Andaluz de la Mujer. Centro de Documentación y Publicaciones, 2003.

Sevilla Merino, J.: Democracia paritaria y Constitución. Seminario «Balance y Perspectivas de los Estudios de las Mujeres y del Género», 2003.

- Igualdad y democracia paritaria. En Democracia paritaria: aportaciones para un debate/coord. por Ángela del Carmen Sierra González, María del Pino de la Nuez Ruiz, 2007, ISBN 978-84-7584-602-6.

- Mujeres y ciudadanía: la democracia paritaria. València: Institut Universitari d'Estudis de la Dona, 2004.

Sevilla Merino, T.; Soler Sánchez, M.; Sevilla Merino, J.: Composición de órganos y democracia paritaria. En Género, constitución y estatutos de autonomía/ coord. por Teresa Freixes Sanjuán, Julia Sevilla Merino, 2005.

Sierra GonzÁlez, A.: Democracia paritaria: aportaciones para un debate. Coord. por, María del Pino de la Nuez Ruiz, Editorial Laertes, 2007.

- La democracia paritaria y las paradojas ocultas de la democracia representativa. En Democracia paritaria: aportaciones para un debate/coord. por Ángela del Carmen Sierra González, María del Pino de la Nuez Ruiz, 2007. 
y Nuez Ruiz, M. DE LA (eds.): Democracia paritaria. Aportaciones para un debate. Juliana Udi, Revista de Filosofía y Teoría Política, nº 39, 2008.

Toboso SÁnchez, P.: Las mujeres en el siglo XXI: igualdad jurídica y discriminación cotidiana. En De la democracia ateniense a la democracia paritaria/coord. por María Pilar Pérez Cantó, 2009.

Torres Muro, I.: El debate jurisprudencial y doctrinal sobre las cuotas electorales de género en España. En Tópicos electorales: un diálogo judicial entre América y Europa/coord. por Luis Efrén Ríos Vega, 2011.

Ventura Franch, A.; Romaní Sancho, L. (coord.): El derecho a la participación política de las mujeres. Resultados de la aplicación de la Ley de igualdad en las elecciones a las Cortes Generales (2004-2008-2011), Tirant lo Blanch, Valencia, 2014.

VIDAl Fueyo, M.: Sobre la legitimidad constitucional de la imposición a los partidos políticos de presentar candidaturas con una composición equilibrada de mujeres y hombre: la STC 12/2008. En Igualdad de género: una visión plural: Jornadas Igualdad Efectiva: realidad o ficción: Burgos 11, 12 y 13 de marzo de 2008/coord. por Esther Gómez Campelo, Félix Valbuena González, 2008.

Vogel-Polsky, E.: Democracia paritaria en Europa. En Políticas de género en la Unión Europea, 2001.

\section{Artículos de Revistas}

Álvarez RodríGuez, I.: ¿Democracia inacabada? Igualdad de género, cuotas electorales y constitución en el ordenamiento jurídico español. CEFLegal: revista práctica de derecho. Comentarios y casos prácticos, nº 91, 2008.

- ¿Es la democracia española paritaria?: la composición equilibrada de las listas electorales en la práctica. En Aequalitas: Revista jurídica de igualdad de oportunidades entre mujeres y hombres, $\mathrm{n}^{\circ} 29,2011$.

: Democracia paritaria. Un estudio crítico, de Elviro Aranda Alvarez. Asamblea: revista parlamentaria de la Asamblea de Madrid, n 29, 2013, p. 413.

: Modelos de democracia paritaria desde una óptica comparada. Revista de estudios políticos, $\mathrm{n}^{\circ} 159,2013$.

- ; Torres Muro, I.: Iguales, pero separados. Las cuotas electorales ante el Tribunal Constitucional (STC 12/2008, de 29 de enero). Repertorio Aranzadi del Tribunal Constitucional, $\mathrm{n}^{\circ}$ 7, 2008.

Aquino De SouzA, C.: Las cuotas electorales y el derecho fundamental de sufragio. Revista jurídica Universidad Autónoma de Madrid, n 17, 2008.

- Las cuotas electorales y los derechos fundamentales. Universitas: Revista de filosofía, derecho y política, ISSN-e 1698-7950, nº 13, 2011.

Biglino CAmpos, P.: Variaciones sobre las listas de composición equilibrada (Comentario a la STC 12/2008). Revista Española de Derecho Constitucional, no 83, Mayo/ Agosto 2008.

BLÁzQuez Vilaplana, B.: Liderazgo político de mujeres: desde la transición hacia la democracia paritaria. Revista de estudios políticos, $\mathrm{n}^{\circ} 128,2005$.

Carballo Fidalgo, M.: El principio de igualdad y la tutela contra la discriminación en la Lei Orgánica de 22 de marzo de 2007 para la Igualdad Efectiva de Mujeres y 
Hombres. En Administración \& cidadanía: revista da Escola Galega de Administración Pública, ISSN-e 1887-0279, Vol. 1, n 3, 2006 (Ejemplar dedicado a: Políticas de igualdad y atención a la dependencia).

Carbonell Sánchez, M.: La reforma al Código Federal de Instituciones y Procedimientos Electorales en materia de cuotas electorales de género. En Cuestiones constitucionales: revista mexicana de derecho constitucional, ISSN-e 1405-9193, n 8 , 2003.

Carmona Cuenca, E.: Las cuotas electorales femeninas: una exigencia del principio de igualdad sustancial (contra el monopolio de los púlpitos). Revista de estudios políticos, $\mathrm{n}^{\circ} 115,2002$.

Ceccherini, E.: La igualdad de sexos en la representación política: la experiencia italiana, en Revista de Derecho Constitucional Europeo, vol. 3, n 6, 2006.

Сово Bedía, R.: Democracia paritaria y radicalización de la igualdad. En Utopías, nuestra bandera: revista de debate político, $\mathrm{n}^{\circ}$ 195, 2003.

- Democracia paritaria y sujeto político feminista. En Anales de la Cátedra Francisco Suárez, no 36, 2002 (Ejemplar dedicado a: El derecho de una democracia cosmopolita).

- Feminismo y democracia paritaria. En El Viejo topo, $\mathrm{n}^{\circ}$ 158, 2001.

: Sexo, democracia y poder político. En Feminismo /s: revista del Centro de Estudios sobre la Mujer de la Universidad de Alicante, n 3, 2004 (Ejemplar dedicado a: Mujer y participación política).

Corona Aguilar, A.: Si ganamos nosotras, gana todo el mundo: importancia de las asociaciones de mujeres en la lucha contra la exclusión social. En Portularia: Revista de Trabajo Social, Vol. 4, 2004 (Ejemplar dedicado a: ¿Es posible otro mundo? V Congresos de Escuelas de Trabajo Social).

CRISTOBAL, R.S.: La presencia de mujeres en los parlamentos autonómicos: La efectividad de las medidas de paridad adoptadas por los partidos políticos y por el legislador. Revista de Estudios Políticos, nº 141, 2008.

Delgado Sotillos, I.: Sistema electoral y representación de las mujeres en elParlamento. Análisis de los efectos de la Ley de Igualdad en la composición del Congreso de los Diputados tras las elecciones legislativas de 2008. Revista de Estudios Políticos, $\mathrm{n}^{\circ} 150$, Octubre/Diciembre 2010.

Dominguez Moreno, M.: Democracia y paridad (democracia paritaria y sujeto político feminista). Cuadernos para el diálogo, n 56 (mayo-junio), 2011.

Feliu, D.: Constitucionalitat de les mesures de democràcia paritària en els sistemes electorals autonòmics. En El Clip, n 20, 2002.

Figueruelo Burrieza, A.: Representación política y democracia paritaria (a propósito de la Sentencia del TC 12/2008, de 29 de enero). Revista europea de derechos fundamentales, no 12, 2008.

: Representación política, derecho de asociación y democracia paritaria. En Letras jurídicas: revista de los investigadores del Instituto de Investigaciones Jurídicas U. V., n $18,2008$.

García Mahamut, R.: Principio de igualdad y derecho de participación en los asuntos públicos en las reformas de la LOREG operadas en la VIII legislatura y en las propuestas de reformas pendientes. En Corts: Anuario de derecho parlamentario, $\mathrm{n}^{\circ} 24$, 
2010 (Ejemplar dedicado a: 25 años de la aprobación de la ley orgánica de régimen electoral general: balance y perspectivas).

García Soriano, M.V.: El principio de presencia equilibrada en el art. 44 bis de la LOREG y el derecho de acceso a los cargos públicos en condiciones de igualdad: análisis crítico de la última reforma de la LOREG. En Feminismo /s: revista del Centro de Estudios sobre la Mujer de la Universidad de Alicante, n ${ }^{\circ}$ 12, 2008 (Ejemplar dedicado a: Mujeres en Democracia: Perspectivas jurídico-políticas de la Igualdad/coord. por María Nieves Montesinos Sánchez, María del Mar Esquembre Valdés).

García-Berrio Hernández, T.: Democracia paritaria, ¿mito o realidad? Francia vs. Suecia: dos perspectivas antagónicas. Anuario de derechos humanos, nº 9, 2008.

González Salcedo, A.: Cuotas, partidos e igualdad en España. Revista de Derecho Electoral, Año 5, no 5, 2011.

Holgado González, M.: Financiación de partidos y democracia paritaria. Revista de estudios políticos, $\mathrm{n}^{\circ} 115,2002$.

Jenson, J.; Valiente Fernández, C.: El movimiento a favor de la democracia paritaria en Francia y España. Revista Española de Ciencia Política, nº 5, 2001.

Lousada Arochena, J.F.: Unos apuntes sobre las llamadas cuotas electorales a la vista de la declaración de su constitucionalidad. Diario La Ley, nº 6918, 2008.

MACÍAs Jara, M.: El principio de presencia equilibrada en la Ley Orgánica para la Igualdad efectiva de mujeres y hombres. Anuario de la Facultad de Derecho, ISSN-e $1697-5723, \mathrm{n}^{\circ} 4,2011$.

- La democracia representativa paritaria: algunas cuestiones en torno a la LO 3/2007, de 22 de marzo. En Aequalitas: Revista jurídica de igualdad de oportunidades entre mujeres y hombres, $\mathrm{n}^{\circ} 23,2008$.

Martínez Alarcón, M.L.: La Ley Orgánica para la igualdad efectiva de mujeres y hombres y la Sentencia del Tribunal Constitucional 12/2008, de 29 de enero. Revista de Estudios Políticos, no 142, Octubre/Diciembre 2008.

Martínez-Carrasco Pignatelli, C.: Igualdad de género y paridad democrática. Cuotas electorales: imposición por ley o libertad de partidos. Revista General de Derecho Administrativo, ISSN-e 1696-9650, nº 6, 2004

Medero, G.S.: Los «sistemas de cuota» y sus efectos en los parlamentos y en los partidos políticos. Revista de Estudios Feministas, v18 n3, 2010.

Naranjo De La Cruz, R.: Fomento de la participación política de la mujer y régimen constitucional de los partidos políticos. Revista de Derecho Político, no 63, 2005.

Peris Cervera, R.M.: Del derecho al voto a la democracia paritaria. Themis: revista jurídica de igualdad de género, $\mathrm{n}^{\circ}$ 1, 2007.

Pinedo Bravo, E.: Las cuotas electorales como medidas de discriminación inversa: algunas notas sobre la denominada «cuota nativa» en Perú. RIPS: Revista de investigaciones políticas y sociológicas, Vol. 9, nº 1, 2010.

Pulido QueCEDo, M.: ¿Hacia una democracia paritaria?: impresiones críticas de la STC 12/20089. Repertorio Aranzadi del Tribunal Constitucional, n ${ }^{\circ}$ 2, 2008.

Rey MARTínez, F.: Cuotas electorales reservadas a mujeres y Constitución, en Aequalitas, $\mathrm{n}^{\circ} 1,1999$.

- La presentación equilibrada en los partidos políticos. Aequalitas: Revista jurídica de igualdad de oportunidades entre mujeres y hombres, nº 20, 2007. 
La presentación equilibrada en los partidos políticos. Cuadernos de Derecho Judicial, $\mathrm{n}^{\circ}$ 5, 2007.

Ricoy CASAS, R.M.: Las cuotas electorales en España. Especial referencia a la doctrina del Tribunal Constitucional. Anuario de la Facultad de Derecho de Ourense, n ${ }^{\circ}$ 1, 2012.

RoccA, M.E.: Soberanía indivisible y democracia paritaria: una reflexión a partir del pensamiento de Derrida. Revista de derecho pùblico, n 42, 2012.

Rodríguez Ruiz, B. y Rubio Marín, R.: De la paridad, la igualdad y la representación en el Estado democrático. Revista Española de Derecho Constitucional, $n^{\circ} 81$, Septiembre/Diciembre 2007.

RoIG, R.M.: La Ley de Igualdad 3/2007 y las elecciones al Congreso de los Diputados de 2004 y 2008, en Working papers, $\mathrm{n}^{\circ}$ 283, Institut de Ciències Politiques i Socials, 2010.

Romero PÉrez, R.: Filosofía, feminismo y democracia en España. En Investigaciones feministas: papeles de estudios de mujeres, feministas y de género, $\mathrm{n}^{\circ} 2,2011$.

Ruiz Miguel, A.: En defensa de las cuotas electorales para la igualdad de las mujeres. En Aequalitas: Revista jurídica de igualdad de oportunidades entre mujeres y hombres, no 20, 2007.

- En defensa de las cuotas electorales para la igualdad de las mujeres. Cuadernos de derecho judicial, $\mathrm{n}^{\circ}$ 5, 2007.

- La representación democrática de las mujeres. Anales de la Cátedra Francisco Suárez, n 35, 2001 (Ejemplar dedicado a: Opinión pública y democracia).

SAlAzAr Benítez, O.: La presencia de la mujer en los cargos públicos representativos, en Cuadernos Constitucionales de la Cátedra Fadrique Furió Ceriol, nº 25, 1998.

Saldaña Díaz, M.: Génesis y promoción de la democracia paritaria en el Consejo de Europa: de la igualdad entre mujeres y hombres como fundamento de la democracia a la participación equilibrada de género en la toma de decisiones política y pública. Revista europea de derechos fundamentales, $\mathrm{n}^{\circ} 22,2013$.

Serra Cristóbal, R.: La presencia de mujeres en los parlamentos autonómicos: la efectividad de las medidas de paridad adoptadas por los partidos políticos y por el legislador. Revista de Estudios Políticos, nº 141, 2008.

Sevilla Merino, J.: Mujeres y hombres en la vida política: las cuotas para mujeres y hombres, $\mathrm{n}^{\circ} 19,2006$.

Torres Muro, I.: Las SSTC 12/2008, de 29 de enero, y 13/2009, de 19 de enero, sobre las cuotas electorales: contenido, recepción y consecuencias. En Aequalitas: Revista jurídica de igualdad de oportunidades entre mujeres y hombres, $\mathrm{n}^{\circ} 24,2009$.

Udi, J.: Democracia paritaria. Aportaciones para un debate. Sierra GonZÁlez, A. y Nuez Ruiz, M.P. de la (eds.) Revista de Filosofía y Teoría Política, nº 39, 2008.

Uribe Otalora, A.: Las cuotas de género y su aplicación en España: los efectos de la Ley de Igualdad (LO 3/2007) en las Cortes Generales y los Parlamentos Autonómicos. Revista de Estudios Políticos, n 160, 2013.

Valiente, C.; Ramiro, L. y Morales, L.: Mujeres en el Parlamento: un análisis de las desigualdades de género en el Congreso de los Diputados, Revista de Estudios Políticos, $\mathrm{n}^{\circ} 121$, Julio/Septiembre 2003.

Verge Mestre, T.: Cuotas de género y reclutamiento político: Análisis del Parlament de Catalunya (1980-2010). Revista española de ciencia política, n 26, 2011. 
Mujeres y partidos políticos en España: las estrategias de los partidos y su impacto institucional, 1978-2004. Revista Española de Investigaciones Sociológicas, jul-sep 2006.

Zoco Zabala, C.: Democracia paritaria en España. Un estudio comparado de las elecciones generales (marzo de 2008) con las elecciones autonómicas (mayo de 2007). Cuadernos del Marqués de San Adrián: revista de humanidades, nº extra 1, 2009 (Ejemplar dedicado a: Ayudas a la investigación 08/09).

ZÚÑIga AÑAZCO, Y.: Democracia paritaria: de la teoría a la práctica. Revista de Derecho, Vol. 18, no 2, 2005.

\section{DEMOCRACIA INTERNA Y PARTIDOS POLÍTICOS}

\section{Libros y Capítulos de Libros}

Alcántara Sáez, M.; Cabezas Rincón, L.M.: Selección de candidatos y elaboración de programas en los partidos políticos latinoamericanos. Valencia, Tirant lo Blanch, 2013.

BARREDO, M.: La democracia interna de los partidos: un desafío del desarrollo. En A los príncipes republicanos: gobernanza y desarrollo desde el republicanismo cívico/ coord. por Joan Prats i Catalá, 2006.

IgLESIAS BÁREZ, M.: La influencia de la sociología política de principios del siglo XX en la construcción del derecho de partidos: la ley de hierro de la oligarquía y la exigencia constitucional de la democracia interna en los partidos políticos. En El derecho, las ciencias y las humanidades/Ángela Figueruelo Burrieza (dir.), Gastón J. Enríquez Fuentes (dir.), Michael Núñez Torres (dir.), 2010.

Maroto Calatayud, M.: Capítulo VI. Autorregulación y legitimidad corporativa: democracia interna y control social en partidos políticos y empresas. En Autorregulación y sanciones/Luis Arroyo Jiménez (dir.), Adán Nieto Martín (dir.), 2008, Lex Nova, Valladolid, 2008.

Orozco Henríquez, J.: La democracia interna de los partidos políticos en Iberoamérica y su garantía jurisdiccional. En Derecho constitucional para el siglo XXI: actas del VIII Congreso Iberoamericano de Derecho Constitucional/coord. por Manuel Carrasco Durán, Francisco Javier Pérez Royo, Joaquín Urías Martínez, Manuel José Terol Becerra, Vol. 2, 2006.

Ostrogorski, M.: La Democracia y los Partidos Políticos. Trotta, Madrid, 2008.

Paneblanco, A.; TRINIDAD, M.: Modelos de partido: organización y poder en los partidos políticos. Madrid, Alianza, 2009.

Pérez-Moneo Agapito, M.: La selección de candidatos electorales en los partidos. Centro de Estudios Políticos y Constitucionales, CEPC, 2012.

SÁnCHEZ Herrera, F.J.: El artículo 6 de la constitución española: la democracia interna de los partidos políticos. En Estudios sobre la constitución española: libro homenaje a Gumersindo Trujillo Fernández/coord. por Manuel Álvarez de la Rosa, Juan Hernández Bravo de Laguna, 2006.

Sánchez Medero, G.: La democracia interna en los partido políticos: el Partido Popular. En Nuevos tiempos, nuevos retos, nuevas sociologías/coord. por Patricia Madrigal Barrón, Elena Carrillo Pascual, 2012. 
TOHARIa Cortés, J.: Los españoles y la democracia interna de los partidos políticos. En El Parlamento ante la crisis: XX Jornadas de la Asociación Española de Letrados de Parlamentos/coord. por Francesc Pau i Vall, Benigno Pendás García, 2014.

\section{Artículos de Revistas}

Alguacil GonzÁlez-Aurioles, J.: De nuevo sobre el poder y los controles a los partidos políticos: a propósito de la reciente reforma de la LOREG sobre mociones de censura en el ámbito municipal Revista general de derecho constitucional, $\mathrm{n}^{\circ} 12$, 2011.

Aquino, J.A.: Partidos políticos y elecciones primarias: construyendo la democracia interna(1). Ciencia y Sociedad. Vol 29, nº 3, 2004.

- Partidos políticos y elecciones primarias: construyendo la democracia interna(2). Ciencia y Sociedad. Vol 30, no 3, 2005.

Barragán Manjón, M.: La selección de candidatos a la Presidencia en el PP y el PSOE: un reflejo de la oligarquía partidaria. RIPS: Revista de investigaciones políticas y sociológicas, Vol. 11, nº 4, 2012.

— : La selección de candidatos a la Presidencia en el PP y el PSOE: un reflejo de la oligarquía partidaria. RIPS: Revista de investigaciones políticas y sociológicas, Vol. 11, no 4, 2012.

Barreiro Carballal, L.: Democracia interna y derecho de asociación. Anuario da Facultade de Dereito da Universidade da Coruña, n ${ }^{\circ}$ 12, 2008.

Freidenberg, F. y SÁnChez López, F.: ¿Cómo se elige un candidato a presidente? Reglas y prácticas en los partidos políticos de América Latina. Revista de Estudios Políticos, no 118, Octubre/Diciembre 2002.

Freidenberg, F.: Democracia interna: reto ineludible de los partidos políticos. Revista de Derecho Electoral, ISSN-e 1659-2069, nº 1, 2006.

Gamboa BArrón, F.: Democracia interna de los partidos políticos. Ars Iuris, $\mathrm{n}^{\circ} 33$, 2005.

Giménez GLuCK, D.: El derecho de asociación de los partidos políticos y la regulación legal de las elecciones primarias. Revista Española de Derecho Constitucional, $\mathrm{n}^{\circ}$ 102, Septiembre/Diciembre 2014.

GonzÁlez Alonso, J.A.: Tareas de Izquierda socialista: organización y democracia interna. En El Viejo topo, no 285, 2011.

GonZÁlEZ García, I.: La selección de candidatos electorales en los partidos políticos. Revista de estudios políticos, $\mathrm{n}^{\circ} 162,2013$.

Hernández VAlle, R.: La democracia interna de los partidos políticos. Revista de derecho político, $\mathrm{n}^{0}$ 53, 2002.

Huneeus, C.: Organización y liderazgo en los partidos políticos: un análisis comparado de Alemania, España y Chile. Revista de Ciencia Política, Vol. 21, no 1, 2001.

Medero, G.S.: El grado de participación y decisión de los afiliados en los partidos políticos: Un estudio comparativo entre el partido popular y el partido socialista obrero español. Argos. V28, n25, 2011.

Morales, G.: Democracia interna en los partidos. En Altar Mayor, nº 132, 2, 2010. 
Noguera, A.: La democracia interna de los partidos políticos. Temas para el debate, $\mathrm{n}^{\circ} 216$ (nov.), 2012 (Ejemplar dedicado a: Los partidos socialdemócratas del siglo $\mathrm{XXI})$.

Nunes, L.F.: Partidos políticos y democracia interna: el diablo está en los detalles. Revista de Derecho Electoral, Año 5, no 5, 2011.

Orozco Henriquez, J.J.: La democracia interna de los partidos políticos en Iberoamérica y su garantía jurisdiccional. Derecho Constitucional para el siglo XXI: Actas del VIII Congreso Iberoamericano de Derecho Constitucional. Vol.2. Ed. Cizur Menor: Thomson Aranzadi, 2006.

Pajin Iraola, L. (entrevistada); Simancas Simancas, R. (entrevistado); Fernández Sanz, M. (entrevistada); Mella Márquez, M. (entrevistado); Sosa Wagner, F. (entrevistado): La democracia en los partidos políticos. En Temas para el debate, $\mathrm{n}^{\circ} 170$ (en.), 2009 (Ejemplar dedicado a: La nueva arquitectura internacional).

Quesada SÁnchez, A.J.: Democracia interna y asociaciones: reflexiones desde una óptica civil (1). Diario La Ley, 2008.

SACRISTÁn Romero, S.: Influencia de las elecciones primarias abiertas en el seno de los partidos políticos latinoamericanos. Revista de Estudios Políticos, n 136, Abril/ Junio 2007.

SÁNCHez Medero, G.: La democracia interna en los partidos políticos españoles: el caso del Partido Socialista Obrero Español (PSOE). Revista de Ciencias Sociales, ISSN-e 1315-9518, Vol. 17, n 4, 2011.

Sobrado GonzÁLEZ, L.A.: Nuevos desafíos de la justicia electoral: la expansión de los derechos políticos y la promoción de la democracia interna de los partidos políticos. Revista de Derecho Electoral, ISSN-e 1659-2069, n 10, 2010.

Vergara Vidal, J.: La desagregación política: Reflexiones sobre la actuación de las élites partidarias en las crisis de los partidos políticos. Polis (Santiago), 2011.

Virgala Foruria, E.: Democracia interna y derechos de los afiliados a los partidos políticos. Revista catalana de dret públic, ISSN-e 1885-8252, nº 37, 2008 (Ejemplar dedicado a: Repensando el Estado democrático).

\section{CORRUPCIÓN Y PARTIDOS POLÍTICOS}

\section{Libros y Capítulos de Libros}

Bonete Perales, E. (ed. lit.): Poder político: límites y corrupción. Cátedra, 2014.

Bustos Gisbert, R.: Corrupción política y derecho. En Estudios sobre la corrupción: una reflexión hispano brasileña/coord. por Ignacio Berdugo Gómez de la Torre, Ana Elisa Liberatore S. Bechara, 2013.

Clemente, J.: El oasis catalán: la corrupción del poder. Madrid: Espejo de Tinta, 2005.

Fernández Ajenjo, J. A.: El Control de las Administraciones Públicas y la Lucha contra la Corrupción. Thompson-Civitas, Madrid, 2011.

Fernández García, J.: Algunas reflexiones sobre la corrupción política. En Estudios sobre corrupción/coord. por Eduardo A. Fabián Caparrós, Ana Isabel Pérez Cepeda, 2010, pp. 39-74. 
García Mexía, P.: Los conflictos de intereses y la corrupción contemporánea. Editorial Aranzadi, 2001.

MAIZ SuÁrez, R.: El clientelismo de partido y la corrupción política. Instituciones y procesos políticos: homenaje al José Cazorla/coord. por Juan Montabes Pereira, 2005, pp. 363-390.

Malavé Osuna, B.: Corrupción política y amistad en la Roma de Cicerón. En El derecho penal: de Roma al derecho actual/coord. por Fermín Camacho de los Ríos, M. Aránzazu Calzada González, 2005, pp. 351-366.

Malem Seña, J. F.: La Corrupción. Aspectos Éticos, Económicos, Políticos y Jurídicos. Gedisa, Barcelona, 2002.

Robles Egea, A.: La democracia imposible: sistemas clientelares y corrupción política. En Joaquín Costa y la modernización de España: ponencias presentadas al Congreso Nacional sobre Costa y la Modernización de España. Madrid, Residencia de Estudiantes, 8-10 de marzo de 2011/coord. por Cristóbal Gómez Benito, 2011, pp. 131-172.

Rose-Ackerman, S.: La Corrupción y los Gobiernos: Causas, Consecuencias y Reforma. Siglo XXI, Madrid, 2001.

Soriano Díaz, R.L.: La corrupción política: tipos, causas y remedios. En Calidad democrática e instituciones políticas/coord. por Ramón Luis Soriano Díaz, María Gloria Trocello, 2011.

Urquiza, J.M.: Corrupción municipal: por qué se produce y cómo evitarla. Almuzara, 2005. Villoria Mendieta, M.: La Corrupción Política. Síntesis, Madrid, 2006.

\section{Artículos de Revistas}

AA.VV.: «Encuesta: Corrupción Política». Teoría y Realidad Constitucional. $\mathrm{n}^{\circ} 25$, UNED, Madrid, 2010.

Bilbao Alberdi, G.: Corrupción (y) política. Crítica, nº 989, 2014 (Ejemplar dedicado a: La corrupción en España).

Bustos Gisbert, R.: «Corrupción Política: Un Analisis desde la Teoría y la Realidad Constitucional». Teoría y Realidad Constitucional. n 25, UNED, Madrid, 2010.

- Corrupción de los gobernantes, responsabilidad política y control parlamentario. Revista Teoría y Realidad Constitucional, Año 2007, nº 19.

- Corrupción política: un análisis desde la teoría y la realidad constitucional. Teoría y realidad constitucional, $\mathrm{n}^{\mathrm{o}} 25,2010$.

Cortina Orts, A.: ¿Cómo superar la crisis moral de la política?. Temas para el debate, $n^{\circ} 223$ (jun.), 2013 (Ejemplar dedicado a: La lucha contra la corrupción).

Dolz Lago, M.J.: Delitos de corrupción política: aspectos concretos. Diario La Ley, $\mathrm{n}^{\mathrm{o}} 8284,2014$.

DurÁn MuÑoz, R.: Corrupción política y movilización electoral de los gerontoinmigrantes europeos en las municipales de 2007. RIPS: Revista de investigaciones políticas y sociológicas, Vol. 12, nº 3, 2013.

- Residentes extranjeros y corrupción política: las elecciones municipales de 2007 en España. Revista española de ciencia política, n 23, 2010. 
Espinel Vallejo, M.: Corrupción política: un nuevo contenido para un viejo debate o un nuevo debate para un viejo contenido. Zona abierta, $n^{\circ}$ 98-99, 2002 (Ejemplar dedicado a: Corrupción política).

GARCIA López, E.: Istorie fiorentine de Maquiavelo: una primera definición moderna de corrupción. Revista Teoría y Realidad Constitucional, Año 2010, nº 25.

- La corrupción ¿un problema jurídico o un estadio sociológico-moral? El Cronista del Estado Social y Democrático de Derecho, n 35, 2013.

García Viñuela, E.; González De Aguilar, C.: Financiación de los partidos y búsqueda de rentas: un análisis de las reformas de la financiación política española de 2007 y 2012. Revista española de ciencia política, n 34, 2014.

Gimeno Sendra, J.V.: Corrupción y propuestas de reforma (1). Diario La Ley, no 7990 , 2012

González Vila, T.: Corrupción política, código ético y código penal. En Acontecimiento: órgano de expresión del Instituto Emmanuel Mounier, ISSN 1698-5486, $\mathrm{n}^{\mathrm{o}} 108,2013$.

JimÉnEZ SÁnCHEZ, F.: Escándalos de corrupción y defectos de la financiación de los partidos políticos en España: situación actual y propuestas. Studia politicae, nº 12, 2007.

Martínez Cousinou, G.: El control de la corrupción política. El fracaso de la reforma de la Ley de Financiación de Partidos Políticos en España. Documentos de trabajo (Instituto de Estudios Sociales Avanzados de Andalucía), nº 3, 2007.

- La corrupción política: nuevas aportaciones para un viejo debate, Revista de estudios políticos, n $133,2006$.

MusacCHIO, V.: Corrupción política y criminalidad organizada: peligrosas connivencias. Revista General de Derecho Penal, ISSN-e 1698-1189, nº 20, 2013.

Ridao Martín, J.: La transparencia y el control económico-financiero de los partidos políticos en España: Entre un balance decepcionante y un futuro sombrío. Revista «Cuadernos Manuel Giménez Abad», nº 7, 2014.

Rubio CARracedo, J.: La fuente de la corrupción política: la teoría de Rousseau sobre las tres voluntades del ciudadano. Revista de Estudios Políticos, n 141, 2008.

Sandoval Coronado, J.C.: Aportación a una reflexión político criminal sobre la corrupción en la financiación de los partidos políticos. Revista General de Derecho Penal, ISSN-e 1698-1189, nº 22, 2014.

Simancas Simancas, R.: El precio de la corrupción. Temas para el debate, no 183 (feb.), 2010 (Ejemplar dedicado a: ¿Qué hacer frente a la corrupción?).

Sola, P.: Los casos de corrupción siguen salpicando instituciones y partidos catalanes. Diario La Ley, $n^{\circ}$ 8039, 2013.

SoriAnO, R.: La corrupción política: tipos, causas y remedios. Anales de la Cátedra Francisco Suárez, no 45, 2011.

Valenciano Martínez-Orozco, M.E.; Blas Guerrero, A. de; Berzosa Alonso-Martínez, C.; Mayor Zaragoza, F.; Cortina Orts, A.; Iglesias FernánDeZ, O.; Llamazares Trigo, G.; Lizcano Álvarez, J.; Villoria Mendieta, M.: Cómo combatir la corrupción. Temas para el debate, nº 221 (abr.), 2013 (Ejemplar dedicado a: ONG's para el desarrollo).

VAnegas Avilés, L.M.: Reflexiones en torno al tema de la corrupción política. En Senderos: revista de ciencias religiosas y pastorales, Año 29, nº 88, 2007 (Ejemplar dedicado a: Ética y Educación). 
VÁzquez Doxa, R.: Corrupción política y responsabilidad de los servidores públicos. Cuadernos de filosofía del derecho, $\mathrm{n}^{\circ}$ 30, 2007.

Villoria, M. y JiméneZ, F.: ¿Cuánta corrupción hay en España? Los problemas metodológicos de la medición de corrupción (2004-2011). Revista de Estudios Políticos, $\mathrm{n}^{\circ}$ 156, Abril/Junio 2012.

\section{PARTIDOS POLÍTICOS Y TERRITORIO}

\section{Libros y Capítulos de Libros}

Alcántara Sáez, M.: Políticos y política en América Latina. Madrid, Fundación Carolina, Siglo XXI, 2006.

—; Muñoz Armenta, A.; Tarrés Barraza, M.L.: Partidos políticos en América Latina: precisiones conceptuales, estado actual y retos futuros. México: Instituto Electoral del Estado de México, 2006.

Berenguer, R.M.: Los efectos del sistema electoral europeo en España: los partidos politicos de ámbito no estatal. Institut de Ciences Politiques i Socials, Barcelona, 2005.

Brown Arauz, H.; Abreu Fernández, V.; E-Libro, corp.: Los partidos políticos en Centroamérica: un estudio institucional comparado sobre la disciplina partidista en Costa Rica, Guatemala y Panama. Madrid. Universidad Complutense de Madrid, 2004.

Catalá i Bas, A.: Libertades. Partidos políticos en la Constitución Europea. Comentarios a la Constitución Europea/coord. por Vicente Garrido Mayol, Susana García Couso, Enrique Alvarez Conde, Vol. 2, 2004 (Los derechos y libertades/coord. por Vicente Garrido Mayol, Enrique Alvarez Conde).

Cortés Bureta, P.: Los partidos políticos europeos: una forma más de integración. En Constitución y democracia: 25 años de Constitución democrática en España: (actas del congreso celebrado en Bilbao los días 19 a 21 de noviembre de 2003)/coord. por Miguel Angel García Herrera, Vol. 2, 2005.

Ferraiuolo, G.: Partidos políticos y autonomía territorial: una reflexión comparada entre Italia y España. En El derecho a decidir, un diálogo italo-catalán: seminario, Barcelona, 22 de octubre de 2013/coord. por Mercè Corretja i Torrens; Laura Capuccio (ed. lit.), 2014, pp. 97-124.

FundaCión ALternativas: Los partidos políticos marroquíes: elecciones legislativas y política exterior: 11 de julio de 2007. El Sáhara occidental: 10 de octubre de 2006. Fundación Alternativas, 2008.

Garzón Clariana, G.: Ciudadanía europea y democracia: la reforma del acta electoral y de los partidos políticos europeos. Madrid, Marcial Pons 2012.

GIRÓN, J.: Los partidos políticos en Asturias (1875-1923): los partidos republicanos, reformista, socialista y comunista. Oviedo, Nobel, 2013.

: Partidos políticos y elecciones municipales en Asturias (1979-2003). Silverio Cañada 2007.

GonzÁlez, A.; López Nieto, L.: Los partidos políticos en el desarrollo autonómico: PSOE-AP/PP. En Relaciones intergubernamentales en la España democrática: intedependencia, autonomía, conflicto y cooperación/coord. por Lourdes López Nieto, 2006. 
Grau Creus, M.: Partidos políticos y estructura territorial: una reflexión comparada entre Italia y España. En El derecho a decidir, un diálogo italo-catalán: seminario, Barcelona, 22 de octubre de 2013/coord. por Mercè Corretja i Torrens; Laura Capuccio (ed. lit.), 2014.

Guillem Carrau, J.: Libertades. Estatuto y financiación de los partidos políticos de dimensión europea. Comentarios a la Constitución Europea/coord. por vicente Garrido Mayol, Susana García Cousao, Enrique Alvarez Conde, Vol. 22004 (Los derechos y libertades/coord. por Vicente Garrido Mayol, Enrique Alvarez Conde).

López De La Fuente, G.; Allue Buiza, A.: Pluralismo político y partidos políticos europeos. Granada, Comares, 2014.

OÑate Rubalcaba, P.: Los partidos políticos y los sistemas de partidos en la Comunidad Valenciana. En El sistema político y administrativo valenciano/José Manuel Canales Aliende (ed. lit.), Manuel Menéndez Alzamora (ed. lit.), 2013.

Orlando Quevedo, H.: Partidos políticos y sindicalismo siglo XX en La Rioja. Córdoba: M.E.L., 2004.

Perez Moneto Agapito, M.: Los partidos políticos a escala europea (artículo 12). En Javier Garcia Roca y Pablo A. Fernández Sánchez: Integración europea a través de derechos fundamentales, CEPC, Madrid, 2009.

Petschen Verdaguer, S.: El eurogesto necesario: crear partidos políticos europeos. En Los Tratados de Roma en su cincuenta aniversario: perspectivas desde la Asociación Española de Profesores de Derecho Internacional y Relaciones Internacionales/ coord. por Francisco Aldecoa Luzárraga, 2008.

Quintanilla Navarro, M.A.: La integración europea y el sistema político español: los partidos políticos españoles ante el proceso de integración europea, 1979-1999. Madrid, Congreso de los Diputados, 2001.

Rivas LeONe, J.A.: Transformaciones y crisis de los partidos politicos: la nueva configuración del sistema de partidos en Venezuela. Barcelona, ICPS, 2002.

Rivera Otero, X.M.; Barreiro Rivas, X.L.; Jimenez, F.; Lagarez Diez, N.: Os partidos políticos en Galicia. Vigo, Xerais, 2003.

Rodríguez Aguilera de Prat, C.: Partidos políticos e integración europea. Barcelona, ICPS, 2008.

ROIG I BerENGUer, R.M.: Los efectos del sistema electoral europeo en España: los partidos politicos de ámbito no estatal. Barcelona, Institut de Ciències Politiques i Socials, 2005.

Ruiz Romero, M.: Tiempos de cambio: Andalucía hacia la Transición autonómica: sociedad, partidos politicos e instituciones. Universidad de Sevilla, Secretariado de Publicaciones Ateneo de Sevilla 2008.

Saenz Lorenzo, A.; Asociación de Extraparlamentarios de las Cortes de AraGÓN, et al.: Memoria de los partidos: crónica de los partidos políticos aragoneses en la época de la Transición. Zaragoza, Asociación de Extraparlamentarios de las Cortes Aragón, 2003.

\section{Artículos de Revistas}

Alcántara Sáez, M.: Partidos políticos en América Latina: precisiones conceptuales, estado actual y retos futuros. Revista de Esttudios Políticos (Madrid), no 124, AbrJun 2004. 
; Llamazares Valduvieco, I.: Partidos políticos, élites parlamentarias y clases sociales en Centroamérica. América Latina Hoy-Universidad de Salamanca, 2006.

—; Freidenberg, F.: Los partidos políticos en América Latina. América Latina hoy: Revista de Ciencias Sociales (Salamanca), n 27, 2001.

Allúe Buiza, A.; López De La Fuente, G.: Los partidos políticos a escala europea. Revista de Derecho de la Unión Europea, n 18,2010 (Ejemplar dedicado a: Sobre el Tratado de Lisboa: algunas perspectivas críticas).

Astudillo Ruiz, J.: Una primera aproximación cuantitativa a la descentralización de los partidos de ámbito estatal en el Estado de las Autonomías: ¿hay diferencias entre el PSOE y el PP? Revista d'etudis autonòmics i federals, $\mathrm{n}^{\circ}$ 10, 2010.

Baras, M.; Barberá, O.; Barrios López, A.; Rodriguez Teruel, J.: Estructuras de opinión en los partidos políticos y competencia multidimensional: el caso de Cataluña (2004). Revista Española de Ciencia Política, nº 22, 2010.

Barberá Aresté, O.: Alianzas políticas y cambio organizativo en los partidos políticos: el impacto de CIU en Unió Democràtica de Catalunya. Revista Española de Ciencia Política, no 21, 2009.

CAMPo, E.; Ramos, R.: La paradoja partidista: institucionalización y representación en los partidos políticos latinoamericanos. América Latina Hoy, 2006.

Catalá i Bas, A.: Partidos políticos en la Constitución europea. Comentarios a la Constitución europea, 2, 2004.

Chofre Sirvent, J.F.: El Parlamento Europeo y el déficit de partidos políticos: el protagonismo de los grupos políticos. Revista de Derecho Constitucional Europeo, $\mathrm{n}^{\circ}$ 11, 2009 (Ejemplar dedicado a: Homenaje a Peter Häberle (I)).

Corral, M.: (Des)confianza en los partidos políticos en América Latina. Revista de Ciencia Política, Vol. 28, no 3, 2008.

Cosano, P.S.: La nacionalización electoral de los partidos políticos en España. Revista Española de Investigaciones Sociológicas, $\mathrm{n}^{\circ}$ 141, 2013.

JiMÉnEZ Rius, M.P.: La importancia de los partidos regionalistas en España: una especial referencia a las Illes Balears. The importance of the regional parties in Spain; A Case Study of the Balears Islands. Revista General de Derecho Constitucional, $\mathrm{n}^{\circ} 12,2011$.

Navia, P.: Partidos políticos como antídoto contra el populismo en América Latina. Revista de Ciencia Política, Vol. 23, nº 1, 2003.

$$
* * *
$$

TITLE: New and old issues of law of political parties in Spain. Bibliographic Repertory (2001-2014)

ABSTRACT: The present repertoire gathers the various doctrinal contributions (books, chapters, critical studies...) which have analyzed the new and old issues of law of political parties in Spain in recent years: political representation, political parties finance, political corruption, banning parties...

RESUMEN: El presente repertorio bibliográfico recoge los diversos estudios (libors, capitulos de libros y artículos de revistas) que han abordado los nuevos y viejos problemas del Derecho de partidos políticos en España en los últimos años: la representación política, financiación de partidos políticos, probibición de partidos... 
KEY WORDS: Law of political parties, political representation, political parties finance, political corruption, banning parties... repertory.

Palabras clave: Derecho de partidos, representación política, financiación de partidos, corrupción política, probibición de partidos, repertorio.

FECHA DE RECEPCIÓN: 20.12.2014

FECHA DE ACEPTACIÓN: 04.02.2015 